\title{
Estimating salt content of vegetated soil at different depths with Sentinel-2 data
}

\author{
Yinwen Chen ${ }^{\text {Equal first author, } 1}$, Yuanlin Qiu ${ }^{\text {Equal first author, } 2 \text {, Zhitao Zhang }}{ }^{\text {Corresp., 2, } 3 \text {, Junrui Zhang }}{ }^{2,3}$, Ce Chen ${ }^{2,3}$, Jia Han ${ }^{2,3}$, \\ Dan Liu ${ }^{2}$ \\ ${ }^{1}$ Department of Foreign Languages, Northwest A\&F University, Yangling, Shaanxi, China \\ 2 College of Water Resources and Architectural Engineering, Northwest A\&F University, Yangling, Shaanxi, China \\ 3 Key Laboratory of Agricultural Soil and Water Engineering in Arid and Semiarid Areas, Ministry of Education, Northwest A\&F University, Yangling, \\ Shaanxi, China \\ Corresponding Author: Zhitao Zhang \\ Email address: zhitaozhang@126.com
}

The accurate and timely monitoring of the soil salt content (SSC) at different depths is the prerequisite for the solution to salinization in the arid and semiarid areas. Sentinel-2 has demonstrated significant superiority in SSC inversion for its higher temporal, spatial and spectral resolution, but previous research on SSC inversion with Sentinel-2 mainly focused on the unvegetated surface soil. Based on Sentinel-2 data, this study aimed to build four machine learning models at five depths $(0 \sim 20 \mathrm{~cm}, 20 \sim 40 \mathrm{~cm}, 40 \sim 60 \mathrm{~cm}, 0 \sim 40 \mathrm{~cm}$, and $0 \sim 60 \mathrm{~cm}$ ) in the vegetated area, and evaluate the sensitivity of Sentinel-2 to SSC at different depths and the inversion capability of the models. Firstly, 117 soil samples were collected from Jiefangzha Irrigation Area (JIA) in Hetao Irrigation District (HID), Inner Mongolia, China during August, 2019. Then a set of independent variables (IVs, including 12 bands and 32 spectral indices) were obtained based on the Sentinel-2 data (released by the European Space Agency), and the full subset selection was used to select the optimal combination of IVs at five depths. Finally, four machine learning algorithms, back propagation neural network (BPNN), support vector machine (SVM), extreme learning machine (ELM) and random forest (RF), were used to build inversion models at each depth.

The model performance was assessed using adjusted coefficient of determination $\left(R_{\text {adj }}^{2}\right)$, root mean square error (RMSE) and mean absolute error (MAE). The results indicated that $20 \sim 40 \mathrm{~cm}$ was the optimal depth for SSC inversion. All the models at this depth demonstrated a good fitting $\left(R_{\text {adj }}^{2} \approx 0.6\right)$ and a good control of the inversion errors (RMSE < $0.16 \%, \mathrm{MAE}<0.12 \%)$. At the depths of $40 \sim 60 \mathrm{~cm}$ and $0 \sim 20 \mathrm{~cm}$ the inversion performance showed a slight and a great decrease respectively. The sensitivity of Sentinel-2 to SSC at different depths was as follows: $20 \sim 40 \mathrm{~cm}>40 \sim 60 \mathrm{~cm}>0 \sim 40 \mathrm{~cm}>$ $0 \sim 60 \mathrm{~cm}>0 \sim 20 \mathrm{~cm}$. All four machine learning models demonstrated good inversion 
performance $\left(R_{\text {adj }}^{2}>0.46\right)$. RF was the best model with high fitting and inversion accuracy. Its $R^{2}$ adj at five depths were between 0.5 to 0.68 . The SSC inversion capabilities of all the four models were as follows: RF model > ELM model > SVM model > BPNN model. This study can provide a reference for soil salinization monitoring in large vegetated area. 


\section{Estimating salt content of vegetated soil at different 2 depths with Sentinel-2 data}

3 Yinwen Chen ${ }^{* 1}$, Yuanlin Qiu ${ }^{* 2}$, Zhitao Zhang ${ }^{2,3}$, Junrui Zhang ${ }^{2,3}$, Ce Chen ${ }^{2,3}$, Jia Han ${ }^{2,3}$, Dan 4 Liu $^{2}$

$5 \quad{ }^{1}$ Department of Foreign Languages, Northwest A\&F University, Yangling, Shaanxi, China

$6 \quad{ }^{2}$ College of Water Resources and Architectural Engineering, Northwest A\&F University,

7 Yangling, Shaanxi, China

$8{ }^{3}$ Key Laboratory of Agricultural Soil and Water Engineering in Arid and Semiarid Areas,

9 Ministry of Education, Northwest A\&F University, Yangling, Shaanxi, China 10

11 Corresponding Author:

12 Zhitao Zhang ${ }^{2,3}$

13 No. 23, Weihui Road, Yangling, Shaanxi, 712100, China

14 Email address: zhitaozhang@126.com 


\section{Abstract}

The accurate and timely monitoring of the soil salt content (SSC) at different depths is the prerequisite for the solution to salinization in the arid and semiarid areas. Sentinel-2 has demonstrated significant superiority in SSC inversion for its higher temporal, spatial and spectral resolution, but previous research on SSC inversion with Sentinel-2 mainly focused on the unvegetated surface soil. Based on Sentinel-2 data, this study aimed to build four machine learning models at five depths $(0 \sim 20 \mathrm{~cm}, 20 \sim 40 \mathrm{~cm}, 40 \sim 60 \mathrm{~cm}, 0 \sim 40 \mathrm{~cm}$, and $0 \sim 60 \mathrm{~cm})$ in the vegetated area, and evaluate the sensitivity of Sentinel-2 to SSC at different depths and the inversion capability of the models. Firstly, 117 soil samples were collected from Jiefangzha Irrigation Area (JIA) in Hetao Irrigation District (HID), Inner Mongolia, China during August, 2019. Then a set of independent variables (IVs, including 12 bands and 32 spectral indices) were obtained based on the Sentinel-2 data (released by the European Space Agency), and the full subset selection was used to select the optimal combination of IVs at five depths. Finally, four machine learning algorithms, back propagation neural network (BPNN), support vector machine (SVM), extreme learning machine (ELM) and random forest (RF), were used to build inversion models at each depth. The model performance was assessed using adjusted coefficient of determination $\left(R^{2} a d j\right)$, root mean square error (RMSE) and mean absolute error (MAE). The results indicated that $20 \sim 40 \mathrm{~cm}$ was the optimal depth for SSC inversion. All the models at this depth demonstrated a good fitting $\left(R^{2}{ }_{a d j} \approx 0.6\right)$ and a good control of the inversion errors (RMSE $<0.16 \%$, MAE $<0.12 \%$ ). At the depths of $40 \sim 60 \mathrm{~cm}$ and $0 \sim 20 \mathrm{~cm}$ the inversion performance showed a slight and a great decrease respectively. The sensitivity of Sentinel-2 to SSC at different depths was as follows: $20 \sim 40 \mathrm{~cm}>40 \sim 60 \mathrm{~cm}>0 \sim 40 \mathrm{~cm}>0 \sim 60 \mathrm{~cm}>0 \sim 20 \mathrm{~cm}$. All four machine learning models demonstrated good inversion performance $\left(R_{a d j}^{2}>0.46\right)$. RF was the best model with high fitting and inversion accuracy. Its $R^{2}$ adj at five depths were between 0.5 to 0.68 . The SSC inversion capabilities of all the four models were as follows: RF model $>$ ELM model $>$ SVM model $>$ BPNN model. This study can provide a reference for soil salinization monitoring in large vegetated area.

\section{Key words}

Sentinel-2; soil salt content; different depths; vegetated area; full subset selection; machine learning

\section{Introduction}

Soil salinization has been an important factor leading to crop yield reduction and land degradation in arid and semiarid areas (Harti et al., 2016). Efficient and accurate monitoring of soil salt content (SSC) on a large scale is the key to tackle this problem. Among the varied monitoring methods, satellite remote sensing has become increasingly prevailing. 
79 So far, different satellites and methods have been applied to soil salinization monitoring. 80 Lobell et al. (2010) first used MODIS data for regional-scale soil salinity assessment and 81 reduced the effect of temporally dynamic factors using the mean of the enhanced vegetation 82 index (EVI) for a 7-year period. With consideration of the effects of precipitation, crop type, and 83 soil texture, Scudiero, Skaggs \& Corwin (2014) assessed the SSC based on the average of multiyear Landsat7 data, and obtained reliable results. Wu et al. (2014b) mapped soil salinity mainly with Landsat ETM+ and MODIS multi-year data, and achieved reliable salinity prediction results in vegetated and non-vegetated areas, respectively. IKONOS data were used to analyze the Pearson correlation coefficient between broadband indices and soil salinity, the results indicated that the correlation depended on the environmental conditions (soil, vegetation cover and density), and vegetation indices performed better in densely vegetated areas (Allbed, Kumar \& Aldakheel, 2014). Landsat 8 data were used to construct 12 VI-SI (vegetation indices-salinity indices) feature spaces based on the information of bare soil and vegetation. Results showed that MSAVI-SI ${ }_{1}$ (modified soil adjust vegetation index-salinity index) can greatly improve the dynamic and periodical monitoring of soil salinity (Guo et al., 2019). These studies on the relationship between multiple satellite data and soil salinity have provided a good basis for regional SSC assessment. However, each of the above satellites has demonstrated such defects as low spatial resolution or small spectral range. Sentinel-2 has shown certain advantages because it simultaneously has high temporal and spatial resolution, which enable more detailed and higherfrequency monitoring for practical applications. Additionally, Sentinel-2 can obtain the red-edge region of vegetation spectrum, which can provide more effective data for vegetation growth monitoring.

Scholars have conducted some research on SSC inversion with Sentinel-2 data. Wang et al. (2020) estimated soil salinity using the machine learning model, Cubist. By comparing the two SSC distribution maps (at the depth of $0 \sim 20 \mathrm{~cm}$ ), they found that Sentinel-2 outperformed Landsat-8 in accuracy. Davis, Wang \& Dow (2019) and Gorji et al. (2020) also discovered that Sentinel-2 had great potential for SSC inversion. Taghadosi, Hasanlou \& Eftekhari (2019) established two models (multiple linear regression and support vector regression) using Sentinel2 images, which had good performance in SSC inversion in the unvegetated areas. Wang et al. (2019a) created multiple spectral indices based on Sentinel-2 data and developed an RF-PLSR model to estimate SSC. The above studies on SSC inversion with Sentinel-2 data were mostly concentrated in the surface soil. Ramos et al. (2020) evaluated soil salinity at the depth of $0 \sim 1.5 \mathrm{~m}$ via multiple stepwise regression based on multi-year Sentinel-2 data, and obtained relatively high prediction accuracy (the coefficient of determination ranged from 0.63 to 0.91 ). This study lays a groundwork for soil salinity estimation at root depth based on Sentinel-2 data. However, the evaluation of SSC at different root depths in the vegetated soil remains to be investigated.

In addition, the machine learning algorithms have been widely used for SSC inversion and water resources management (Wang et al., 2019a). Chen et al. (2015) studied the accuracy of multiple linear regression (MLR), back propagation neural network (BPNN), and support vector 
119 machine (SVM) in soil salinity estimation using hyperspectral data, and found that BPNN and

120 SVM were more accurate than MLR. When studying the hybrid particle swarm optimization

121 with extreme learning machine (ELM) for daily reference evapotranspiration $\left(\mathrm{ET}_{0}\right)$ prediction

122 from limited climatic data, Zhu et al. (2020) explored the ability of artificial neural networks

123 (ANN), random forests (RF) and other empirical algorithms in estimating daily $\mathrm{ET}_{0}$. The results

124 indicated that the machine learning models outperformed the corresponding empirical

125 algorithms. Machine learning algorithms are available for SSC inversion, and yet the accuracy of

126 each algorithm using Sentinel-2 data to estimate SSC needs more in-depth comparison.

127 SSC evaluation at different root depths in the vegetated soil and the algorithm accuracy in

128 SSC estimation via Sentinel-2 data both demands further research. Therefore, this study used the

129 Sentinel-2 images of Jiefangzha Irrigation Area (JIA) in the vegetated area to construct the set of

130 independent variables (IVs, including 12 bands and 32 spectral indices). Next, the optimal

131 combinations of IVs at five depths $(0 \sim 20 \mathrm{~cm}, 20 \sim 40 \mathrm{~cm}, 40 \sim 60 \mathrm{~cm}, 0 \sim 40 \mathrm{~cm}$, and $0 \sim 60 \mathrm{~cm})$

132 were obtained using full subset selection. Finally, four machine learning algorithms, back

133 propagation neural network (BPNN), support vector machine (SVM), extreme learning machine

134 (ELM) and random forest (RF), were used to construct inversion models (models for SSC

135 estimation via satellite data) and evaluate the sensitivity of Sentinel-2 to SSC at different depths

136 and the inversion capability of the models.

\section{Materials \& Methods}

\section{Study area}

139 The study area, JIA, is located in the northwest of Hetao Irrigation District (HID), Inner

140 Mongolia, China, between $106^{\circ} 34^{\prime} \sim 107^{\circ} 34^{\prime} \mathrm{E}$, and $40^{\circ} 26^{\prime} \sim 41^{\circ} 13^{\prime} \mathrm{N}$, which is the same as that

141 of Qiu et al. (2019). JIA, an oblique triangular area about $86 \mathrm{~km}$ long and $81 \mathrm{~km}$ wide, is the

142 second largest irrigation area in HID. With an altitude of about $1030 \mathrm{~m}$ to $1046 \mathrm{~m}$, this plateau is

143 high in the southwest, low in the northeast, and relatively flat on the whole. It is located in an

144 arid and semiarid area with a temperate continental climate. The annual mean temperature,

145 annual precipitation and evaporation are $4 \sim 6^{\circ} \mathrm{C}, 66.3 \sim 200 \mathrm{~mm}$ and 1920 3450 mm, respectively.

146 Moreover, the annual precipitation distribution is uneven (the precipitation in summer accounts

147 for about $70 \%$ of the year). JIA is $2156.7 \mathrm{~km}^{2}$ in total, about $57.5 \%$ of which is irrigatable. The

148 crop planting structure is complex, and the crops mainly include corn, wheat, sunflower and so

149 on. The local climate and hydrological conditions determine the dependence of the crop growth

150 in this area mainly on the irrigation from the Yellow River. The annual water diversion in JIA is

151 about 1.2 billion $\mathrm{m}^{3}$, and the land is mainly irrigated in summer and autumn. The water diversion

152 in October accounts for about $30 \%$ of the annual amount. Fig. 1A shows the specific

153 geographical location of the study area.

154 Soil sample collection and analysis

155 The Hetao irrigation district administration gave field permit approval to us (No.

156 2017YFC0403302). Among the main crops in JIA, sunflower, corn and zucchini are usually

157 harvested around September 20. Therefore, August 25 30, 2019, when the crops were

158 flourishing and the vegetation information was abundant, was chosen as the study period. We 
159 collected 117 soil samples ( 83 covered with sunflowers, 10 cabbages, 10 corns, 2 wheats, 2

160 vegetables, and 10 bare soil) (Fig. 1B) when the types of underlying surface, salinization degree,

161 and evenness of point distribution were taken into consideration. According to the root depth of

162 the crops and related research results (Qiao, 2005; Zhang et al., 2019b), we selected 0 20cm、

$16320 \sim 40 \mathrm{~cm}$ and $40 \sim 60 \mathrm{~cm}$ as the sampling depth. We adopted the five-point sampling method so

164 that each of the 117 soil samples was the mixed soil from one center and four corner points in a

165 cell $(0.5 \mathrm{~m} \times 0.5 \mathrm{~m})$. The GPS data and environment information of the center point were recorded

166 during the sampling.

167 Measurement of SSC

168 The soil samples were first dried, ground, and then screened with a 2.0-mm sieve to remove

169 the small stones and wood pieces. The processed samples were mixed with water to make soil

170 solution (the ratio of soil to water is 1:5). Eight hours after the solution was prepared, its

171 electrical conductivity $\left(\mathrm{EC}_{1: 5}, \mathrm{ds} / \mathrm{cm}\right)$ was measured by conductivity meter (DDS-307A;

172 Shanghai Youke Instrument Branch, Shanghai, China), and then the SSC (\%) was calculated by

173 the empirical formula (1), which was developed by Huang et al. (2018) in their research in HID.

174

175

176

177

178

179

180

181

182

183

184

185

186

187

188

189

$$
S S C=\left(0.2882 \times \mathrm{EC}_{1: 5}\right)+0.0183
$$

\section{Statistical characteristics of SSC}

We selected five depths $(0 \sim 20 \mathrm{~cm}, 20 \sim 40 \mathrm{~cm}, 40 \sim 60 \mathrm{~cm}, 0 \sim 40 \mathrm{~cm}$ and $0 \sim 60 \mathrm{~cm})$ in this study, and the SSC of $0 \sim 40 \mathrm{~cm}$ was the mean value of $0 \sim 20 \mathrm{~cm}$ and $20 \sim 40 \mathrm{~cm}$ and that of $0 \sim 60 \mathrm{~cm}$ was the mean value of $0 \sim 20 \mathrm{~cm}, 20 \sim 40 \mathrm{~cm}$ and $40 \sim 60 \mathrm{~cm}$. The sample points were sequenced according to the SSC, and then one of every three samples were selected as the validation dataset so that the ranges of calibration and validation datasets were consistent and evenly distributed. The statistical characteristics of SSC are shown in Table 1.

\section{Sentinel-2 image data}

Sentinel-2 consists of two satellites (Sentinel-2A and 2B), and both provide multi-scale (10m, $20 \mathrm{~m}$ and $60 \mathrm{~m}$ ) remote sensing images via MultiSpectral Instrument (MSI). It has a 5-day revisiting period when the two satellites are combined. It has 13 bands (440nm 2200nm), including visible light, near infrared and short-wave infrared bands. Three of the bands can obtain the red-edge region of vegetation spectrum $(670 \mathrm{~nm} \sim 760 \mathrm{~nm})$, which can provide more effective data for vegetation growth monitoring. The remote sensing image data for this study were taken from Sentinel-2A, and its parameters of each band are shown in Table 2.

The satellite images in this study were obtained from the website (https://scihub.copernicus.eu/) of the European Space Agency (ESA), on August 28, 2019, which was basically synchronous with the sampling time and there was no cloud in the study area. The Sentinel-2 data used in this study were Level-2A products (Bottom-Of-Atmosphere reflectance images), which were produced by the plug-in Sen2cor (Level-2A product can also be obtained directly from ESA since December 2018). Then all the bands were resampled to $10 \mathrm{~m}$ via the S2

197 Resampling Processor in software SNAP (the bicubic method was used for resampling). As band

198 B10 was not available when the images were processed to Level-2A, the other 12 bands were used in this study. 


\section{Extraction and selection of spectral index}

200

201

202

203

204

205

206

207

208

209

210

211

212

213

214

215

216

217

218

219

220

221

222

223

224

225

226

227

228

229

230

231

232

233

234

\section{Selection of spectral index}

In this study, we selected 32 widely used spectral indices, including salinity index, vegetation index and drought index. The indices and the relevant formulae are shown in Table 3.

\section{Soil line fitting}

As has been shown in the Nir-Red scatterplot of several studies, when the horizontal and vertical coordinates are the red and Nir bands, respectively, a series of corresponding points of the digital number values of the red and Nir infrared wavelengths of the bare soil approximate to fit into a straight line, which is called soil line ( Wu et al., 2014a). Three spectral indices (PVI, PDI and VAPDI) used in this study were based on the concept of soil line. Eight hundred pure bare pixels (NDVI $<0.1$ ) were identified by visual interpretation using conventional soil line extraction for soil line fitting. $R^{2}, M$, and $I$ were $0.9694,1.0984$, and 0.0152 , respectively (Fig. 2).

\section{Full subset selection}

According to the least squares method, the full subset selection is a method to select the optimal combinations by traversing all possible combinations of the full IV set (the IV set includes 12 bands and 32 indices). The calculation of the full subset selection takes the following steps: When the number of IVs is $P, P$ models can be built according to $K$, the number of IVs input into the model $\left(1 \leq K \leq P, K\right.$ is integer), and there are $C_{P}^{K}$ combinations of IVs for each model (Zhang et al., 2019b). Therefore, based on the calibration dataset, the optimal combination of the IVs for each model was selected according to the maximum of the adjusted coefficient of determination $\left(R^{2}{ }_{a d j}\right)$. Afterwards, based on the $R^{2}$ adj, root mean square error (RMSE), mean absolute error (MAE), Akaike information criterion (AIC) and Bayesian information criterion (BIC), the optimal model from P models at each depth was selected on the ground of the validation dataset. Considering the computational magnitude problem of full subset selection, the value of $K$ was taken from 2 to 6 .

Among the five criteria, $R_{a d j}^{2}$ can improve the accuracy of the comparison between the models with different numbers of IVs and samples. As the number of IVs in the model increases, $R^{2}{ }_{a d j}$ will not necessarily increase (Srivastava, Srivastava \& Ullah, 1995), which mitigates the difference among the coefficient of determination caused by the number of IVs. RMSE and MAE are indicators to evaluate the model inversion error; AIC and BIC measure the goodness of model fit. Smaller values of AIC and BIC mean the model can explain the dependent variable (DV) with fewer IVs (Atkinson et al., 2012). The equations are shown in (2), (3), (4), (5) and (6). 
235

236

237

238

239

240

241

242

243

244

245

246

247

248

249

250

251

252

253

254

255

256

257

258

259

260

261

262

263

264

265

266

267

268

269

270

271

272

273

274

$$
A I C=2 k+n[\ln (R S S)]
$$

$$
B I C=n\left[\ln \left(\hat{\sigma}^{2}\right)\right]+k \times \ln (n)
$$

where $\hat{y}_{i}, y_{i}$ and $\bar{y}$ are the predicted, measured, and the average of measured values of the model, respectively; $n$ is the number of samples; $k$ is the number of free parameters in the model; RSS is the squared sum of the residuals between the measured and predicted data; $\hat{\sigma}^{2}$ is the error variance.

\section{Construction of machine learning models}

Four machine learning algorithms, BPNN, SVM, ELM and RF were selected for SSC estimation. Fig. 3 is the flowchart of the proposed methodology of SSC estimation in this study. BPNN Model

BPNN algorithm, proposed by Rumelhart, Hinton \& Williams (1986), has a strong nonlinear mapping capability and can adjust the internal parameters of the system according to the error between the output and actual value via the error back propagation algorithm. Topologically, the BPNN model consists of three layers: the input, hidden, and output layers (Fig. 4) (Wang et al., 2018). After extensive pre-testing, the BPNN model in this study used the optimal combination of IVs as the input layer, SSC as the output layer, and the number of hidden layers was set as 2. The transfer functions of the input and output layers were linear, and the hidden layers were tangent-S. The target error and network learning rate were $0.65 \times 10^{-3}$ and 0.05 , respectively. In order to eliminate the effect of different dimensions on data analysis, the input layer and output layer data were normalized (so were the other three models). MATLAB was used to build the BPNN model (so were the other three models). Details of BPNN can be found in Xiao et al. (2020) and Chen et al. (2015).

\section{SVM Model}

SVM is a machine learning algorithm based on the principle of structural risk minimization. It focuses on transforming the input data into a high-dimensional feature space using nonlinear transformations for classification and regression (Chen et al. 2015). This algorithm enjoys such advantages as avoiding discrete values, mitigating overlearning and reducing computation. This study adopted the widely used radial basis kernel (RBF) (Zhang et al., 2019b) as the kernel function of SVM. The penalty parameter $(C)$ and the nuclear parameter $(g)$ of the RBF have a great effect on the model stability, so a grid-searching technique was used to find the best parameters of $C$ and $g$ (at $0 \sim 20 \mathrm{~cm}, 20 \sim 40 \mathrm{~cm}, 40 \sim 60 \mathrm{~cm}, 0 \sim 40 \mathrm{~cm}$ and $0 \sim 60 \mathrm{~cm}$, the $C$ was 724, $1024,1024,1024$ and 1024, respectively, the $g$ was $0.0313,0.0028,0.0039,0.0156$ and 0.01 , respectively).

\section{ELM Model}

ELM is a machine learning algorithm proposed by Huang, Zhu\& Siew (2006). It is the same as BPNN in structure, a traditional three-layer neural network (Fig. 4). Its main difference is that the execution does not require adjustments to the input weights of the network or the biases of the hidden elements. Therefore, ELM can reduce the influence of such subjective factors as choice of parameters, and speed up computation while ensure accuracy (Ahila, Sadasivam \& Manimala, 2015; Prasad et al., 2019). After extensive pre-testing, this study adopted sigmoid as 
275 the activation function, and the number of hidden nodes was set as 6. Detailed principles of ELM

276 can be found in Zhu et al. (2020).

277 RF Model

278 RF is a machine learning algorithm proposed by Breiman (2001). Based on multiple decision

279 tree theory, this algorithm can be used for classification and regression. RF uses the bootstrap

280 method to extract training sets from the input data, and randomly generates variables to build

281 decision tree models. Thus, the decision made by a random forest model is based on the

282 ensemble of decisions made by numerous decision trees (Fig. 5) (Zhou et al., 2020; Du et al.,

283 2015). After extensive pre-testing, the minimum number of observations per tree leaf (minleaf)

284 and the number of decision trees (ntree) were set as 5 and 10, respectively (the two parameters

285 were determined by the out-of-bag errors and training set cross-validation) (Zhang et al., 2019a).

286 Model accuracy evaluation

$287 R_{a d j}^{2}$, RMSE, and MAE were used to evaluate the inversion of calibration and validation

288 model. Among the three criteria, $R_{a d j}^{2}$ can avoid the errors caused by the different number of IVs

289 in each model. The closer its value is to 1 , the better fit the model has. The smaller the RMSE

290 and MAE are, the smaller the deviation between the predicted and measured values are. The

291 equations are shown in (2), (3) and (4).

292 Results and analysis

293 Analysis of correlation between SSC and IVs

294 We selected 12 bands of Sentinel-2 and 32 spectral indices to form the IV set for SSC

295 inversion. Based on the calibration dataset, the correlation between the IVs and SSC was

296 analyzed, as is shown in Fig. 6.

297 The significance level between the IVs and SSC was tested according to the significance

298 testing table of correlation coefficient. When the degree of freedom was 78 and the absolute

299 value of the correlation coefficient $(R)$ was greater than 0.221 , the significance level reached

3000.05 , and when $\mathrm{R}$ was greater than 0.288 , the significance level reached 0.01 . At all five depths

$301(0 \sim 20 \mathrm{~cm}, 20 \sim 40 \mathrm{~cm}, 40 \sim 60 \mathrm{~cm}, 0 \sim 40 \mathrm{~cm}$ and $0 \sim 60 \mathrm{~cm})$, the significance level between eight

302 IVs (B6, SI2, S1, S2, S6, BI, SMMI, and PDI) and SSC failed to reach 0.05, that between six IVs

303 (B7, B8, B8A, Int2, NSDSI3, and VSDI) and SSC reached the 0.05, and that between the

304 remaining 30 IVs and SSC reached 0.01.

305 Optimal combination of IVs based on full subset selection

306 In order to identify the optimal combinations of IVs, we took the SSC as the DV, and the least

307 squares as the method for data fitting on the basis of the calibration dataset. Then we obtained

308 the optimal combination when the number of IVs was 2 to 6 at the five depths $(0 \sim 20 \mathrm{~cm}, 20 \sim 40$

$309 \mathrm{~cm}, 40 \sim 60 \mathrm{~cm}, 0 \sim 40 \mathrm{~cm}$ and $0 \sim 60 \mathrm{~cm})$ and calculated the $R^{2}{ }_{a d j}$, RMSE, MAE, AIC and BIC

310 based on the validation dataset (Table 4).

$311 R_{a d j}^{2}$ demonstrated a tendency of rising and then falling when the number of IVs increased at

312 most depths, and this tendency was especially obvious at the depths of $20 \sim 40 \mathrm{~cm}, 40 \sim 60 \mathrm{~cm}$ and

$3130 \sim 60 \mathrm{~cm}$. This indicated that the model fitting became better when the number of IVs was on the

314 rise, but too many IVs would complicate the model, leading to some overfitting. RMSE and 
315 MAE displayed the opposite tendency of $R_{a d j}^{2}$ : they first fell and then rose. This indicated that a 316 local optimal solution might be generated and the validation model error might be increased 317 when there were too many IVs. The tendency of AIC and BIC was almost the same, when the 318 number of IVs increased, there was a first-falling-and-then-rising tendency at $20 \sim 40 \mathrm{~cm}, 40 \sim 60$ $\mathrm{cm}$ and $0 \sim 60 \mathrm{~cm}$, and a tendency of increase at $0 \sim 20 \mathrm{~cm}$ and $0 \sim 40 \mathrm{~cm}$.

At $0 \sim 20 \mathrm{~cm}$, when the numbers of IVs were 2 (IV-2) and 6 (IV-6), the $R^{2}{ }_{a d j}$ was the highest (both were 0.44), and those of the RMSE and MAE were relatively close. However, the AIC of IV-2 was half of that of IV-6, suggesting that IV-2 was able to explain the DV with fewer IVs. Therefore, B1 and NSDSI 3 were the optimal combination of IVs at $0 \sim 20 \mathrm{~cm}$. At $20 \sim 40 \mathrm{~cm}$, the $R^{2}{ }_{a d j}$ of the IV-3 was 0.58 , which was significantly higher than that of the other combinations. The remaining criteria of IV-3 were the lowest, indicating a small error and a high goodness of fit. Therefore, S5, SI-T and NDDI were the optimal combination of IVs at $20 \sim 40 \mathrm{~cm}$. The tendency at $40 \sim 60 \mathrm{~cm}$ was the same as that at $20 \sim 40 \mathrm{~cm}$. IV-3 had the highest $R^{2}{ }_{a d j}$, relatively lower errors and higher goodness of fit at the same time. Therefore, S6, VSDI and NDDI were the optimal combination of IVs at $40 \sim 60 \mathrm{~cm}$. At $0 \sim 40 \mathrm{~cm}$, the $R_{a d j}^{2}$ of IV-2 to IV-4 were all above 0.45 , but the AIC and BIC of IV-2 were the lowest among the three. IV-2 needed the smallest number of IVs to achieve a better fit. Therefore, B1 and NSDSI3 were the optimal combination of IVs at $0 \sim 40 \mathrm{~cm}$. At $0 \sim 60 \mathrm{~cm}$, the $R^{2}{ }_{a d j}$ of IV-3 to IV-6 were all above 0.44 , and the AIC and BIC of IV-3 were the lowest (3.6 and -133, respectively). The RMSE and MAE were relatively low. Therefore, B1, PVI and NSDSI3 were the optimal combination of IVs at $0 \sim 60 \mathrm{~cm}$.

The optimal combination (after the full subset selection) of IVs at each depth was input into the BPNN model for training to obtain the SSC inversion model. The accuracy of calibration and validation models are shown in Table 5.

The model performance was optimal at $20 \sim 40 \mathrm{~cm}$, with the $R^{2}$ adj of around 0.6 for both calibration and validation models, indicating a good fitting and generalization performance. Its RMSE $(0.15 \%)$ and MAE $(0.11 \%)$ were relatively low, indicating their good control of inversion errors. The model had the worst performance at $0 \sim 20 \mathrm{~cm}$, with the lowest $R_{a d j}^{2}$ (below 0.48 ) of the calibration and verification model, and the RMSE (both above $0.17 \%$ ) and MAE $(0.13 \%$ ) were the highest at the five depths. At $40 \sim 60 \mathrm{~cm}$, the model performance was second only to $20 \sim 40 \mathrm{~cm}$, with a relatively good fitting and low inversion error. The performance of the model at $0 \sim 40 \mathrm{~cm}$ and $0 \sim 60 \mathrm{~cm}$ was similar. The $R^{2}{ }_{a d j}$ and MAE were around 0.51 and $0.12 \%$, respectively, but the RMSE at $0 \sim 40 \mathrm{~cm}$ was greater than that at $0 \sim 60 \mathrm{~cm}$, suggesting that some samples had some relatively big errors.

Overall, the BPNN model worked best at $20 \sim 40 \mathrm{~cm}$, followed by $40 \sim 60 \mathrm{~cm}$, and worked worst 353 at $0 \sim 20 \mathrm{~cm}$. The other two depths had better similar results.

\section{Analysis of SVM model}


354

355

356

357

358

359

360

361

362

363

364

365

366

367

368

369

370

371

372

373

374

375

376

377

378

379

380

381

382

383

384

385

386

387

388

389

390

391

392

The optimal combination (after the full subset selection) of IVs at each depth was input into the SVM model for training to obtain the SSC inversion model. The accuracy of calibration and validation models are shown in Table 6.

The model performance was optimal at $40 \sim 60 \mathrm{~cm}$, with $R_{a d j}^{2}$ of 0.58 and 0.55 for the calibration and validation models, respectively, and its RMSE and MAE were the lowest. The performance of the model at $20 \sim 40 \mathrm{~cm}$ and $0 \sim 40 \mathrm{~cm}$ was similar, second only to $40 \sim 60 \mathrm{~cm}$. Comparatively, 20 40 cm was slightly better in fitting of validation model. At $0-20 \mathrm{~cm}$, the model performance was still the worst. Its RMSE (above $0.16 \%$ ) and MAE (above $0.12 \%$ ) indicated a bad control of inversion error. But its $R^{2}{ }_{a d j}$ was around 0.5 , the model at this depth still had a good fitting. At $0 \sim 60 \mathrm{~cm}$, the $R_{a d j}^{2}$ of the calibration and verification models were 0.59 and 0.52 , respectively, showing a slight overfitting.

Overall, the SVM model worked best at $40 \sim 60 \mathrm{~cm}$, followed by $20 \sim 40 \mathrm{~cm}$ and $0 \sim 40 \mathrm{~cm}$. The worst performance of the model was found at $0 \sim 20 \mathrm{~cm}$.

\section{Analysis of ELM model}

The optimal combination (after the full subset selection) of IVs at each depth was input into the ELM model for training to obtain the SSC inversion model. The accuracy of calibration and validation models are shown in Table 7.

The model performance was optimal at $20 \sim 40 \mathrm{~cm}$, with the highest $R_{a d j}^{2}$ (above 0.6 ) and lowest inversion error. The model was still the worst at $0 \sim 20 \mathrm{~cm}$, mainly because the inversion error was the largest. But it still had a good fitting $\left(R^{2} a d j \approx 0.5\right)$. The performance of the model at $0 \sim 60 \mathrm{~cm}$ was slightly better than that at $0 \sim 20 \mathrm{~cm}$. The model performance was satisfactory and similar at 40 60 $\mathrm{cm}$ and $0 \sim 40 \mathrm{~cm}$.

In general, the ELM model worked best at $20 \sim 40 \mathrm{~cm}$, but worst at $0 \sim 20 \mathrm{~cm}$ and $0 \sim 60 \mathrm{~cm}$ (0 60 $\mathrm{cm}$ was slightly better). This model had relatively good performance at the other two depths.

\section{Analysis of RF model}

The optimal combination (after the full subset selection) of IVs at each depth was input into the RF model for training to obtain the SSC inversion model. The accuracy of calibration and validation models are shown in Table 8 .

The RF model performed well at all five depths, with $R^{2}{ }_{a d j}$ all above 0.5 . The model performance was still optimal at $20 \sim 40 \mathrm{~cm}$. The $R^{2}{ }_{a d j}$ of the calibration and validation models were 0.68 and 0.63 , respectively, which were significantly better than at the other depths. Its RMSE (below 0.14\%) and MAE (below 0.11\%) indicated that the inversion error was well controlled. At $0 \sim 40 \mathrm{~cm}$, the model performance was second only to that at $20 \sim 40 \mathrm{~cm}$. The result was worst at $0 \sim 60 \mathrm{~cm}$. Its RMSE and MAE were around $0.15 \%$ and $0.12 \%$, respectively, indicating a relatively high inversion error. However, its $R_{a d j}^{2}$ also reached 0.53 . The model performance at $0 \sim 20 \mathrm{~cm}$ was slightly better than that at $0 \sim 60 \mathrm{~cm}$ because the former's $R^{2}{ }_{a d j}$ of the calibration and validation models were higher ( 0.03 and 0.01 higher, respectively) than that of the latter. There was some overfitting at $40 \sim 60 \mathrm{~cm}$. 
393

394

395

396

397

398

399

400

401

402

403

404

405

406

407

408

409

410

411

412

413

414

415

416

417

418

419

420

421

422

423

424

425

426

427

428

429

430

431

In general, the RF model had a good performance at all depths, working best at $20 \sim 40 \mathrm{~cm}$. The performance was relatively poor at $0 \sim 20 \mathrm{~cm}$ and $0 \sim 60 \mathrm{~cm}(0 \sim 20 \mathrm{~cm}$ was slightly better). The scatterplot of measured and predicted SSC of the four models at the best depth are shown in Fig. 7.

\section{Evaluation of the overall inversion performance} Evaluation of inversion depths

The inversion performance of each model at different depths has been discussed in detail (the Section of Model calibrations and validations). In this section, the sensitivity of Sentinel-2 to SSC at different depths was evaluated by analyzing the combined performance of all models at each depth (Fig. 8). At $20 \sim 40 \mathrm{~cm}$, the $R_{a d j}^{2}$ was significantly higher overall than that of other depths (Fig. 8A-E), and each model was able to achieve a good fitting and generalization performance. At this depth, the RMSE and MAE of the calibration models were the lowest, and those of the validation models were also relatively low (Fig. 8F-O). It indicated that all models were able to control the inversion errors at $20 \sim 40 \mathrm{~cm}$. Therefore, $20 \sim 40 \mathrm{~cm}$ was the optimal depth for the Sentinel-2 data for SSC inversion. The $R_{a d j}^{2}$ at $0 \sim 20 \mathrm{~cm}$ and $0 \sim 60 \mathrm{~cm}$ was relatively low overall, and the inversion error at $0 \sim 20 \mathrm{~cm}$ was the highest among all depths (Fig. 8). The overall fitting at $40 \sim 60 \mathrm{~cm}$ and $0 \sim 40 \mathrm{~cm}$ was satisfactory, and the inversion error at $40 \sim 60 \mathrm{~cm}$ was better controlled (Fig. 8). Therefore, Sentinel-2 had the worst sensitivity at $0 \sim 20 \mathrm{~cm}$. At $0 \sim 60 \mathrm{~cm}$, it was slightly better than $0 \sim 20 \mathrm{~cm}$. The inversion performance was good at $40 \sim 60 \mathrm{~cm}$ and $0 \sim 40 \mathrm{~cm}$, and that at $40 \sim 60 \mathrm{~cm}$ was relatively better.

As is analyzed above, the sensitivity of Sentinel-2 to SSC at different depths in the vegetated area was as follows: $20 \sim 40 \mathrm{~cm}>40 \sim 60 \mathrm{~cm}>0 \sim 40 \mathrm{~cm}>0 \sim 60 \mathrm{~cm}>0 \sim 20 \mathrm{~cm}$.

\section{Evaluation of inversion models}

In this section, the SSC inversion ability of each model was evaluated by analyzing the combined performance at all depths of each model (Fig. 9). The overall $R^{2}{ }_{a d j}$ of the RF model was higher than that of the other models (Fig. 9A-D). Although some overfitting occurred at 40 60 cm, the model still had a good fitting and generalization performance. The RF model had the lowest RMSE and MAE at all depths (Fig. 9E-L), and the inversion error was especially well controlled at $0 \sim 20 \mathrm{~cm}$ where the inversion errors of other models were all high. Therefore, the RF model was the optimal model for SSC inversion. The BPNN model fits relatively poorly at most depths (Fig. 9A-D), and the MAE of BPNN model was high at all depths (Fig. 9I-L). Therefore, the BPNN model had a relatively slightly poor SSC inversion ability. The SVM and ELM models had better fitting and generalization performance, and their inversion errors were relatively low (Fig. 9). The ELM model was obviously better for the inversion at 20 40 cm than that of SVM model. Therefore, both of them have satisfactory SSC inversion performance though ELM model was slightly better.

When $R_{a d j}^{2}$, RMSE and MAE were all taken into consideration, the SSC inversion capability of all models was as follows: RF model $>$ ELM model $>$ SVM model $>$ BPNN model.

\section{SSC distribution of JIA}


432

433

434

435

436

437

438

439

440

441

442

443

444

445

446

447

448

449

450

451

452

453

454

455

456

457

458

459

460

461

462

463

464

465

466

467

468

469

470

471

The optimal model (RF) was used to estimate the SSC distribution at 5 depths $(0 \sim 20$ $\mathrm{cm}, 20 \sim 40 \mathrm{~cm}, 40 \sim 60 \mathrm{~cm}, 0 \sim 40 \mathrm{~cm}$ and $0 \sim 60 \mathrm{~cm}$ ) of JIA (Fig. 10). The study area was interspersed with salinized soil in different degree. It was dominated by non-saline ( $\mathrm{SSC}<0.2 \%)$ and slightly saline soil $(0.2 \%<\mathrm{SSC}<0.5 \%)$. The severely saline $(0.5 \%<\mathrm{SSC}<1 \%)$ and saline soil (SSC $>1 \%$ ) only account for a small portion and mainly distributed in the northwest of the area. The salinization in the south of the area was lower than that in the north, which may be related to the irrigation method of JIA (the water was drained from the south to the north, and salt was accumulated in the north). There was more slightly and severely saline soil at $0 \sim 20 \mathrm{~cm}$ than at 20-40 cm and 40-60 cm, and more non-saline soil at 20 40 cm than at other depths. Overall, the estimated SSC distribution of JIA in this study was consistent with the actual measured information (Huang et al., 2018).

\section{Discussion}

In this study, the full subset selection was used to select the optimal combination of IVs (included 12 bands and 32 spectral indices) at five depths, which mitigated the subjectivity of IV selection. In addition, $R^{2}$ adj was used to evaluate the fitting so as to mitigate the difference among the coefficient of determination caused by the number of IVs. Therefore, the reliability of the comparison of inversion performance at different depths was improved. This study found that Sentinel-2 was most sensitive to SSC at $20 \sim 40 \mathrm{~cm}$, followed by $40 \sim 60 \mathrm{~cm}$, and the sensitivity at other depths from high to low was $0 \sim 40 \mathrm{~cm}, 0 \sim 60 \mathrm{~cm}$ and $0 \sim 20 \mathrm{~cm}$. A similar result was obtained by Zhang et al. (2019b) when studying the sensitivity to SSC at different depths based on GF-1. It has been found that SSC around crop roots can affect the crop growth by producing osmotic stress (Chen et al., 2003). When studying the water absorption model of crop root system in salinization soil in HID, Qiao (2005) found that the main water absorption layer of sunflowers (accounting for $70 \%$ of the samples in our study) was at $0 \sim 50 \mathrm{~cm}$, and the peak of maximum water absorption was at $20 \sim 40 \mathrm{~cm}$. When the sunflower was in bloom (mid to late August), the surface soil moisture content could not meet the root demand, and the peak of maximum water absorption shifted to $35 \mathrm{~cm}$. During this period, the water absorption rate at $20 \sim 40 \mathrm{~cm}$ and $40 \sim 60 \mathrm{~cm}$ was 2 and 1.5 times of that at $0 \sim 20 \mathrm{~cm}$, respectively, and the water increment mainly came from the deep soil layer. Therefore, the SSC at $20 \sim 40 \mathrm{~cm}$ had the strongest effect on crop growth (crop growth can be reflected indirectly via remote sensing data), followed by 40 60 cm, which was basically consistent with the results in our study.

Four machine learning algorithms (BPNN, SVM, ELM, and RF) were used for SSC inversion, and the RF model was found to perform well at all depths and was the optimal model for SSC inversion. This is due to the fact that the RF model is a collection of decision trees, which enables RF to have a good generalization performance and effectively limit the overfitting without reducing the prediction accuracy. The RF model has been found to have a good control over the noise (Belgiu \& Drăguț, 2016; Taghizadeh-Mehrjardi et al., 2020). Therefore, although the variability of SSC was high (CV was about $80 \%$ ), the model could well cope with the outliers and avoid local optimal solutions. By comparing the SSC inversion accuracy used BPNN, SVM, multiple linear regression (MLR) and RF methods, Zhang et al. (2019a) found that the RF model 
472 performed optimally. Others (Pahlavan-Rad et al., 2020; Chagas et al., 2016; Li et al., 2020)

473 have also obtained satisfying results when using RF model for prediction.

474 However, due to the different response mechanisms to SSC at different crop growth period, 475 and the effect of different crop planting structure on the inversion, the conclusions of this study 476 to some extent only apply to the crop planting structure and growth period of this experiment. In 477 addition, this study was limited to the analysis of the statistical relationship between SSC and 478 spectral reflectance, and the response mechanism between the two needs to be analyzed in more 479 depth. Further studies can focus on evaluating the model performance at different crop growth 480 period and structure, and analyzing the response mechanism of SSC, vegetation and spectrum.

\section{Conclusions}

482 This study evaluated the sensitivity of Sentinel-2 to SSC at different depths in the vegetated 483 area, and obtained the optimal estimating model. It can provide a certain basis for soil salinization monitoring in HID. 1. By analyzing the combined performance of all models (after full subset selection) at each depth, we found Sentinel-2 was most sensitive to SSC at $20 \sim 40 \mathrm{~cm}$, the $R^{2}{ }_{a d j}$ of each model was around 0.6 , which was significantly better than that at the other depths. It was the worst at $0 \sim 20$ $\mathrm{cm}$, but the $R^{2}$ adj could also reach 0.45 in each model. The sensitivity of Sentinel-2 to SSC at different depths in the vegetated area was as follows: $20 \sim 40 \mathrm{~cm}>40 \sim 60 \mathrm{~cm}>0 \sim 40 \mathrm{~cm}>0 \sim 60$ $\mathrm{cm}>0 \sim 20 \mathrm{~cm}$.

2. According to the analysis of the combined performance at all depths of each model, we found that all four machine learning models have achieved good inversion results $\left(R_{a d j}^{2}>0.46\right)$. The $\mathrm{RF}$ was the optimal model for SSC inversion. It had obvious advantages in both fitting and inversion accuracy, with $R_{a d j}^{2}$ between 0.5 0.68 at all depths. The SSC inversion ability in the vegetated area of all models was as follows: RF model $>$ ELM model $>$ SVM model $>$ BPNN model.

\section{Acknowledgements}

The authors would like to thank the Key Laboratory of Agricultural Soil and Water Engineering in Arid and Semiarid Areas of Ministry of Education for providing the test equipment. The authors are especially grateful to the reviewers and editors for appraising our manuscript and for offering instructive comments. References

Ahila R, Sadasivam V, Manimala K. 2015. An integrated PSO for parameter determination and feature selection of ELM and its application in classification of power system disturbances. Applied Soft Computing 32. Allbed A, Kumar L, Aldakheel YY. 2014a. Assessing soil salinity using soil salinity and vegetation indices derived from IKONOS high-spatial resolution imageries: Applications in a date palm dominated region. Geoderma 230231:1-8. 10.1016/j.geoderma.2014.03.025. Atkinson PM, Jeganathan C, Dash J, Atzberger C. 2012. Inter-comparison of four models for smoothing satellite sensor time-series data to estimate vegetation phenology. Remote Sensing of Environment 123. 
512 Breiman L. 2001. Random forests. Machine Learning 45:5-32. 10.1023/A:1010933404324.

513 Chen HY, Zhao GX, Liu YQ, Chen JC, Zhang H. 2015. Hyperspectral Estimation Models for the Saline Soil

514 Salinity in the Yellow River Delta. Applied Mechanics and Materials 738-739:197-203.

515 10.4028/www.scientific.net/AMM.738-739.197.

516 Chen Y, Wei Z, Shi H, Qu Z, Kong D, Zhang L, Huo Z. 2003. Evaluation of Crop-water-salt Stress and Response

517 Model Researches. Journal of Irrigation and Drainage:1-6 [in Chinese].

518 Cho KH, Beon M, Jeong J. 2018. Dynamics of soil salinity and vegetation in a reclaimed area in Saemangeum,

519 Republic of Korea. Geoderma 321.

520 Davis, Wang, Dow. 2019. Comparing Sentinel-2 MSI and Landsat 8 OLI in soil salinity detection: a case study of

521 agricultural lands in coastal North Carolina. International Journal of Remote Sensing 40.

522 Du P, Samat A, Waske B, Liu S, Li Z. 2015. Random Forest and Rotation Forest for fully polarized SAR image

523 classification using polarimetric and spatial features. Isprs Journal of Photogrammetry and Remote Sensing 105:38-

524 53. 10.1016/j.isprsjprs.2015.03.002.

525 Gorji T, Yildirim A, Hamzehpour N, Tanik A, Sertel E. 2020. Soil salinity analysis of Urmia Lake Basin using

526 Landsat-8 OLI and Sentinel-2A based spectral indices and electrical conductivity measurements. Ecological

527 Indicators 112.

528 Guo B, Han B, Yang F, Fan Y, Jiang L, Chen S, Yang W, Gong R, Liang T. 2019. Salinization information

529 extraction model based on VI - SI feature space combinations in the Yellow River Delta based on Landsat 8 OLI

530 image. Geomatics, Natural Hazards and Risk 10.

531 Gu F. 2019. Dynamic Monitoring of Vegetation Participants in Typical Oasis Based on Sentinel-2 Data. MA. Eng.

532 thesis, Xinjiang University [in Chinese].

533 Harti AE, Lhissou R, Chokmani K, Ouzemou J, Hassouna M, Bachaoui EM, Ghmari AE. 2016. Spatiotemporal

534 monitoring of soil salinization in irrigated Tadla Plain (Morocco) using satellite spectral indices. International

535 Journal of Applied Earth Observations and Geoinformation 50.

536 Huang G, Zhu Q, Siew C. 2006. Extreme learning machine: Theory and applications. Neurocomputing 70:489-501.

537 10.1016/j.neucom.2005.12.126.

538 Huang Q, Xu X, Lu L, Ren D, Ke J, Xiong Y, Huo Z, Huang G. 2018. Soil salinity distribution based on remote

539 sensing and its effect on crop growth in Hetao Irrigation District. Transactions of the Chinese Society of Agricultural

540 Engineering 34:102-109 [in Chinese].

541 Khaled HQKH. 2017. A remote sensing-based agricultural drought indicator and its implementation over a semi-

542 arid region, Jordan. Journal of Arid Land 9:319-330. 10.1007/s40333-017-0014-6.

543 Li M, Zhang Y, Wallace J, Campbell E. 2020. Estimating annual runoff in response to forest change: A statistical

544 method based on random forest. Journal of Hydrology 589:125168. 10.1016/j.jhydrol.2020.125168.

545 Lobell DB, Lesch SM, Corwin DL, Ulmer MG, Anderson KA, Potts DJ, Doolittle JA, Matos MR, Baltes MJ. 2010.

546 Regional-scale Assessment of Soil Salinity in the Red River Valley Using Multi-year MODIS EVI and NDVI.

547 Journal of Environmental Quality 39:35-41. 10.2134/jeq2009.0140.

548 Pahlavan-Rad MR, Dahmardeh K, Hadizadeh M, Keykha G, Mohammadnia N, Gangali M, Keikha M, Davatgar N, 549 Brungard C. 2020. Prediction of soil water infiltration using multiple linear regression and random forest in a dry

550 flood plain, eastern Iran. Catena 194:104715. 10.1016/j.catena.2020.104715.

Peer] reviewing PDF | (2020:08:51893:1:1:NEW 1 Nov 2020) 
551 Prasad R, Deo RC, Li Y, Maraseni T. 2019. Weekly soil moisture forecasting with multivariate sequential, ensemble 552 empirical mode decomposition and Boruta-random forest hybridizer algorithm approach. Catena 177.

553 Qiao D. 2005. Study on the Energy of SPAC System and Root Uptake Model in Saline Soil. MA. Eng. thesis, Inner 554 Mongolia Agricultural University [in Chinese].

555 Qiu Y, Chen C, Han J, Wang X, Wei S, Zhang Z. 2019. Satellite Remote Sensing Estimation Model of Soil Salinity 556 in Jiefangzha Irrigation under Vegetation coverage. Water Saving Irrigation:108-112 [in Chinese].

557 Ramos TB, Castanheira N, Oliveira AR, Paz AM, Darouich H, Simionesei L, Farzamian M, Gonçalves MC. 2020.

558 Soil salinity assessment using vegetation indices derived from Sentinel-2 multispectral data. application to Lezíria

559 Grande, Portugal. Agricultural Water Management 241:106387. 10.1016/j.agwat.2020.106387.

560 Rumelhart DE, Hinton GE, Williams RJ. 1986. Learning representations by back-propagating errors. Nature

561 (London) 323:533-536. 10.1038/323533a0.

562 Scudiero E, Skaggs TH, Corwin DL. 2014. Regional scale soil salinity evaluation using Landsat 7, western San

563 Joaquin Valley, California, USA. Geoderma Regional 2-3:82-90. 10.1016/j.geodrs.2014.10.004.

564 Scudiero E, Skaggs TH, Corwin DL. 2015. Regional-scale soil salinity assessment using Landsat ETM + canopy

565 reflectance. Remote Sensing of Environment 169:335-343. 10.1016/j.rse.2015.08.026.

566 Srivastava AK, Srivastava VK, Ullah A. 1995. The coefficient of determination and its adjusted version in linear

567 regression models. Econometric Reviews 14:229-240. 10.1080/07474939508800317.

568 Taghadosi MM, Hasanlou M, Eftekhari K. 2019. Retrieval of soil salinity from Sentinel-2 multispectral imagery.

569 European Journal of Remote Sensing 52:138-154. 10.1080/22797254.2019.1571870.

570 Taghizadeh-Mehrjardi R, Mahdianpari M, Mohammadimanesh F, Behrens T, Toomanian N, Scholten T, Schmidt K.

571 2020. Multi-task convolutional neural networks outperformed random forest for mapping soil particle size fractions

572 in central Iran. Geoderma 376:114552. 10.1016/j.geoderma.2020.114552.

573 Triki Fourati H, Bouaziz M, Benzina M, Bouaziz S. 2015. Modeling of soil salinity within a semi-arid region using

574 spectral analysis. Arabian Journal of Geosciences 8:11175-11182. 10.1007/s12517-015-2004-3.

575 Wang J, Ding J, Yu D, Ma X, Zhang Z, Ge X, Teng D, Li X, Liang J, Lizaga L, Chen X, Yuan L, Guo Y. 2019a.

576 Capability of Sentinel-2 MSI data for monitoring and mapping of soil salinity in dry and wet seasons in the Ebinur

577 Lake region, Xinjiang, China. Elsevier 353.

578 Wang J, Ding J, Yu D, Teng D, He B, Chen X, Ge X, Zhang Z, Wang Y, Yang X, Shi T, Su F. 2020. Machine

579 learning-based detection of soil salinity in an arid desert region, Northwest China: A comparison between Landsat-8

580 OLI and Sentinel-2 MSI. Science of the Total Environment 707:136092. 10.1016/j.scitotenv.2019.136092.

581 Wang S, Li R, Li X. 2019b. Inversion and distribution of soil moisture in belly of Maowusu sandy land based on

582 comprehensive drought index. Transactions of the Chinese Society of Agricultural Engineering 35:113-121.

583 10.11975/j.issn.1002-6819.2019.13.012 [in Chinese].

584 Wang X, Zhang F, Ding J, Kung H, Latif A, Johnson VC. 2018. Estimation of soil salt content (SSC) in the Ebinur

585 Lake Wetland National Nature Reserve (ELWNNR), Northwest China, based on a Bootstrap-BP neural network 586 model and optimal spectral indices. Science of the Total Environment 615.

587 Wu C, Qin Q, Li M, Zhang N. 2014a. Soil moisture monitoring of vegetative area in farmland by remote sensing 588 based on spectral feature space. Transactions of the Chinese Society of Agricultural Engineering 30:106-112 [in 589 Chinese]. 
590 Wu W, Al-Shafie WM, Mhaimeed AS, Ziadat F, Nangia V, Payne WB. 2014b. Soil Salinity Mapping by Multiscale

591 Remote Sensing in Mesopotamia, Iraq. IEEE Journal of Selected Topics in Applied Earth Observations and Remote

592 Sensing 7:4442-4452. 10.1109/JSTARS.2014.2360411.

593 Xiao X, Kim J, Hong M, Yang S, Kim Y. 2020. RSM and BPNN Modeling in Incremental Sheet Forming Process

594 for AA5052 Sheet: Multi-Objective Optimization Using Genetic Algorithm. Metals 10:1003. 10.3390/met10081003.

595 Yue J, Tian J, Tian Q, Xu K, Xu N. 2019. Development of soil moisture indices from differences in water

596 absorption between shortwave-infrared bands. Isprs Journal of Photogrammetry and Remote Sensing 154:216-230.

597 10.1016/j.isprsjprs.2019.06.012.

598 Zhang Z, Han J, Wang X, Chen H, Wei G, Yao Z. 2019b. Soil Salinity Inversion Based on Best Subsets-Quantile

599 Regression Model. Transactions of the Chinese Society for Agricultural Machinery 50:142-152 [in Chinese].

600 Zhang Z, Wei G, Yao Z, Tan C, Wang X, Han J. 2019a. Soil Salt Inversion Model Based on UAV Multispectral

601 Remote Sensing. Transactions of the Chinese Society for Agricultural Machinery 50:151-160 [in Chinese].

602 Zhou X, Lu P, Zheng Z, Tolliver D, Keramati A. 2020. Accident Prediction Accuracy Assessment for Highway-Rail

603 Grade Crossings Using Random Forest Algorithm Compared with Decision Tree. Reliability Engineering \& System

604 Safety 200:106931. 10.1016/j.ress.2020.106931.

605 Zhu B, Feng Y, Gong D, Jiang S, Zhao L, Cui N. 2020. Hybrid particle swarm optimization with extreme learning

606 machine for daily reference evapotranspiration prediction from limited climatic data. Computers and Electronics in

607 Agriculture 173:105430. 10.1016/j.compag.2020.105430. 


\section{Table $\mathbf{1}$ (on next page)}

\section{Statistical characteristics of SSC.}

In this table, SSC is soil salt content, SD is standard deviation, CV is coefficient of variation, and the Number refers to the number of sampling points. 


\begin{tabular}{llllllll}
\hline $\begin{array}{l}\text { Depth } \\
(\mathrm{cm})\end{array}$ & Dataset & Number & Min. (\%) & Max. (\%) & Average (\%) & SD (\%) & CV (\%) \\
\hline \multirow{3}{*}{$0 \sim 20$} & Total & 117 & 0.069 & 1.66 & 0.30 & 0.26 & 88.4 \\
& Calibration & 78 & 0.069 & 1.66 & 0.30 & 0.28 & 92.2 \\
& Validation & 39 & 0.076 & 1.26 & 0.29 & 0.23 & 80.6 \\
\hline \multirow{2}{*}{$20 \sim 40$} & Total & 117 & 0.070 & 1.40 & 0.28 & 0.23 & 82.6 \\
& Calibration & 78 & 0.070 & 1.40 & 0.27 & 0.22 & 82.1 \\
& Validation & 39 & 0.082 & 1.27 & 0.29 & 0.24 & 84.3 \\
\hline \multirow{2}{*}{$40 \sim 60$} & Total & 117 & 0.082 & 1.48 & 0.28 & 0.22 & 79.7 \\
& Calibration & 78 & 0.083 & 1.48 & 0.28 & 0.23 & 81.6 \\
& Validation & 39 & 0.082 & 1.15 & 0.28 & 0.22 & 76.6 \\
\hline \multirow{2}{*}{$0 \sim 40$} & Total & 117 & 0.070 & 1.40 & 0.29 & 0.24 & 83.1 \\
& Calibration & 78 & 0.070 & 1.40 & 0.29 & 0.24 & 84.5 \\
& Validation & 39 & 0.079 & 1.26 & 0.29 & 0.24 & 81.4 \\
\hline \multirow{2}{*}{$0 \sim 60$} & Total & 117 & 0.075 & 1.43 & 0.28 & 0.23 & 80.0 \\
& Calibration & 78 & 0.075 & 1.43 & 0.28 & 0.23 & 81.1 \\
& Validation & 39 & 0.085 & 1.22 & 0.29 & 0.23 & 78.9 \\
\hline
\end{tabular}

1 
Table 2 (on next page)

Sentinel-2A band parameters. 


\begin{tabular}{lll}
\hline Band & Band center $(\mathrm{nm})$ & Spatial resolution $(\mathrm{m})$ \\
\hline B1 (Coastal aerosol) & 443.9 & 60 \\
B2 (Blue) & 496.9 & 10 \\
B3 (Green) & 560.0 & 10 \\
B4 (Red) & 664.5 & 10 \\
B5 (Red-edge 1) & 703.9 & 20 \\
B6 (Red-edge 2) & 740.2 & 20 \\
B7 (Red-edge 3) & 782.5 & 20 \\
B8 (NIR) & 835.1 & 10 \\
B8A (Narrow NIR) & 864.8 & 20 \\
B9 (Water Vapor) & 945.0 & 60 \\
B10 (Cirrus) & 1373.5 & 60 \\
B11 (SWIR1) & 1613.7 & 20 \\
B12 (SWIR2) & 2202.4 & 20 \\
\hline
\end{tabular}




\section{Table 3 (on next page)}

Spectral indices.

In this table, $\mathrm{M}$ is the slope of soil line, $I$ is the intercept of soil line, $A$ is the PVI maximum point. The fitting result of soil line is shown in Fig. 2. 


\begin{tabular}{|c|c|c|}
\hline Spectral index & formula & Reference \\
\hline Salinity Index (SI) & $\sqrt{B 2 \times B 4}$ & \multirow{11}{*}{$\begin{array}{l}\text { (Allbed, Kumar \& } \\
\text { Aldakheel, 2014b) }\end{array}$} \\
\hline Salinity Index-2 (SI2) & $\sqrt{B 3^{2}+B 4^{2}+B 8 A^{2}}$ & \\
\hline Salinity Index 3 (SI3) & $\sqrt{B 3^{2}+B 4^{2}}$ & \\
\hline Salinity Index (S1) & $B 2 / B 4$ & \\
\hline Salinity Index (S2) & $(B 2-B 4) /(B 2+B 4)$ & \\
\hline Salinity Index (S3) & $(B 3 \times B 4) / B 2$ & \\
\hline Salinity Index (S5) & $(B 2 \times B 4) / B 3$ & \\
\hline Salinity Index (S6) & $(B 4 \times B 8 A) / B 3$ & \\
\hline Salinity Index-T (SI-T) & $(B 4 / B 8 A) / 100$ & \\
\hline Normalized Difference salinity Index (NDSI) & $(B 4-B 8 A) /(B 4+B 8 A)$ & \\
\hline Brightness Index (BI) & $\sqrt{B 4^{2}+B 8 A^{2}}$ & \\
\hline Canopy Response Salinity Index (CRSI) & $\sqrt{\frac{B 8 A \times B 4-B 3 \times B 2}{B 8 A \times B 4+B 3 \times B 2}}$ & $\begin{array}{l}\text { (Scudiero, Skaggs \& } \\
\text { Corwin, 2015) }\end{array}$ \\
\hline Intensity index 1 (Int1) & $(B 3+B 4) / 2$ & \multirow{2}{*}{$\begin{array}{l}\text { (Triki Fourati et al., } \\
\text { 2015) }\end{array}$} \\
\hline Intensity index 2 (Int2) & $(B 3+B 4+B 8 A) / 2$ & \\
\hline Normalized Vegetation Index (NDVI) & $(B 8 A-B 4) /(B 8 A+B 4)$ & $\begin{array}{l}\text { (Cho, Beon \& Jeong, } \\
\text { 2018) }\end{array}$ \\
\hline Enhanced Vegetation Index (EVI) & $\frac{2.5 \times(B 8 A-B 4)}{(B 8 A+6 \times B 4-7.5 \times B 2+1)}$ & (Qiu et al., 2019) \\
\hline Red Edge Position Index ( $\left.\mathrm{S} 2_{\mathrm{REP}}\right)$ & $705+\frac{35 \times((B 4+B 7) / 2-B 5)}{(B 6-B 5)}$ & \multirow{6}{*}{$(G u, 2019)$} \\
\hline $\begin{array}{l}\text { Normalized Difference Vegetation Index red-edge } 1 \\
\text { (NDVIrel) }\end{array}$ & $(B 8 A-B 5) /(B 8 A+B 5)$ & \\
\hline $\begin{array}{l}\text { Normalized Difference Vegetation Index red-edge } 2 \\
\text { (NDVIre2) }\end{array}$ & $(B 8 A-B 6) /(B 5+B 6)$ & \\
\hline Normalized Difference red-edge 1 (NDre1) & $(B 6-B 5) /(B 6+B 5)$ & \\
\hline Normalized Difference red-edge 2 (NDre2) & $(B 7-B 5) /(B 7+B 5)$ & \\
\hline Triangular Chlorophyll Index red-edge 1 (TCIrel) & $1.2 \times(B 5-B 3)-1.5 \times(B 4-B 3) \times \sqrt{B 5 / B 4}$ & \\
\hline Modified soil-adjusted Vegetation Index (MSAVI) & $2 \times B 4+1-\sqrt{(2 \times B 8 A+1)^{2}-8 \times(B 8 A-B 4)}$ & \multirow{4}{*}{$\begin{array}{l}\text { (Wang, Li R \& Li X, } \\
2019 b)\end{array}$} \\
\hline Normalized Difference Drought Index (NDDI) & $\begin{array}{c}2 \\
(N D V I-N D W I) /(N D V I+N D W I)\end{array}$ & \\
\hline Soil Moisture Monitoring Index (SMMI) & $\sqrt{B 8 A^{2}+B 11^{2}} / \sqrt{2}$ & \\
\hline Perpendicular Vegetation Index (PVI) & $|B 8 A-M \times B 4-I| / \sqrt{M^{2}+1}$ & \\
\hline Perpendicular Drought Index (PDI) & $(B 4+M \times B 8 A) / \sqrt{M^{2}+1}$ & \multirow[t]{2}{*}{ (Wu et al., 2014a) } \\
\hline $\begin{array}{l}\text { Vegetation Adjusted Perpendicular Drought Index } \\
\text { (VAPDI) }\end{array}$ & $P D I(A)-\frac{|P D I(A)-P D I(X)| \times P V I(A)}{P V I(A)-P V I(X)}$ & \\
\hline $\begin{array}{l}\text { Normalized Shortwave-infrared Di } \square \text { erence SM Index } \\
3 \text { (NSDSI3) }\end{array}$ & $(B 11-B 12) /(B 11+B 12)$ & (Yue et al., 2019) \\
\hline Normalized Multiband Drought Index (NMDI) & $\frac{B 8 A-(B 11-B 12)}{B 8 A+(B 11+B 12)}$ & \multirow{3}{*}{ (Khaled, 2017) } \\
\hline Normalized Difference Water Index (NDWI) & $(B 8 A-B 11) /(B 8 A+B 11)$ & \\
\hline Visible and Shortwave Drought Index (VSDI) & $1-(B 12+B 4-2 \times B 2)$ & \\
\hline
\end{tabular}




\section{Table 4(on next page)}

Optimal combination of IVs based on full subset selection.

In this table, ${ }^{* *}$ means reaching the significance level of $0.01, *$ means reaching the significance level of 0.05 , and the bold part represents the optimal combination out of the optimal combinations of IVs at each depth. 


\begin{tabular}{|c|c|c|c|c|c|c|c|}
\hline $\begin{array}{l}\text { Depth } \\
\text { (cm) }\end{array}$ & IV & Optimal combinations & $\mathrm{R}_{\text {adj }}^{2}$ & $\begin{array}{l}\text { RMSE } \\
(\%)\end{array}$ & $\begin{array}{l}\text { MAE } \\
(\%)\end{array}$ & AIC & $\mathrm{BIC}$ \\
\hline \multirow{5}{*}{$0 \sim 20$} & 2 & B1 $^{* *} 、$ NSDSI3 $^{* *}$ & 0.44 & 0.17 & 0.13 & 8.8 & -130 \\
\hline & 3 & $\mathrm{~B}^{* *} 、 \mathrm{NSDSI}^{* *} 、 \mathrm{NMDI}^{* *}$ & 0.43 & 0.17 & 0.13 & 11.3 & -126 \\
\hline & 4 & $\mathrm{~B}^{* *}, \mathrm{~B} 11^{* *}, \mathrm{NSDSI}^{* *}, \mathrm{SMMI}$ & 0.40 & 0.18 & 0.13 & 15.0 & -120 \\
\hline & 5 & $\mathrm{~B} 1^{* *}, \mathrm{~B} 11^{* *}, \mathrm{~B} 12^{* *}, \mathrm{~S} 2_{\mathrm{REP}^{* *}}, \mathrm{PVI}^{* *}$ & 0.33 & 0.19 & 0.14 & 21.5 & -112 \\
\hline & 6 & $\mathrm{~B}^{* *} 、 B 8 A^{* *} 、 B 12^{* *} 、$ NDre2 ${ }^{* *} 、$ NSDSI3 $^{* * *} 、$ SMMI & 0.44 & 0.17 & 0.13 & 16.5 & -115 \\
\hline \multirow{5}{*}{$20 \sim 40$} & 2 & S6、 $\mathrm{NDDI}^{* *}$ & 0.44 & 0.18 & 0.14 & 12.4 & -126 \\
\hline & 3 & S5 $^{* *}$, SI-T $^{* *} 、$ NDDI $^{* *}$ & 0.58 & 0.15 & 0.12 & 2.7 & -134 \\
\hline & 4 & $\mathrm{SI}^{* *}, \mathrm{NDWI}^{* *} 、 \mathrm{NDDI}^{* *} 、 \mathrm{NMDI}^{* *}$ & 0.50 & 0.17 & 0.13 & 12.1 & -123 \\
\hline & 5 & $\mathrm{NDVI}^{* *}, \mathrm{TCIrel}^{* *}, \mathrm{NDWI}^{* *} 、 \mathrm{NDDI}^{* *} 、 \mathrm{NMDI}^{* *}$ & 0.42 & 0.18 & 0.14 & 19.9 & -114 \\
\hline & 6 & $\mathrm{NDVI}^{* *}, \mathrm{~S}_{2} \mathrm{REP}^{* *}, \mathrm{TCIrel}^{* *}, \mathrm{NDWI}^{* *} 、 \mathrm{NDDI}^{* *}, \mathrm{NMDI}^{* *}$ & 0.35 & 0.19 & 0.14 & 26.4 & -105 \\
\hline \multirow{5}{*}{$40 \sim 60$} & 2 & S6、 NDDI $^{* *}$ & 0.38 & 0.16 & 0.12 & 6.2 & -132 \\
\hline & 3 & S6、VSDI" NDDI ${ }^{* *}$ & 0.53 & 0.14 & 0.11 & -2.5 & -139 \\
\hline & 4 & $\mathrm{~B}^{* *}, \mathrm{NDWI}^{* *}, \mathrm{NDDI}^{* *} 、 \mathrm{NMDI}^{* *}$ & 0.45 & 0.16 & 0.12 & 5.9 & -129 \\
\hline & 5 & $\mathrm{NDVI}^{* *} 、 \mathrm{NDVIre}^{* *} 、 \mathrm{NDWI}^{* *} 、 \mathrm{NDDI}^{* *} 、 \mathrm{NMDI}^{* *}$ & 0.38 & 0.16 & 0.12 & 12.2 & -121 \\
\hline & 6 & $\mathrm{S3}^{* *}, \mathrm{NDVI}^{* *}, \mathrm{NDVIre}^{* *} 、 \mathrm{NDWI}^{* *}, \mathrm{NDDI}^{* *}, \mathrm{NMDI}^{* *}$ & 0.34 & 0.17 & 0.13 & 16.4 & -116 \\
\hline \multirow{5}{*}{$0 \sim 40$} & 2 & $\mathrm{B1}^{* *} 、 \mathrm{NSDSI3}^{* *}$ & 0.45 & 0.17 & 0.13 & 6.5 & -132 \\
\hline & 3 & $\mathrm{~B}^{* *} 、 \mathrm{NSDSI}^{* *} 、 \mathrm{NMDI}^{* *}$ & 0.45 & 0.17 & 0.13 & 8.7 & -128 \\
\hline & 4 & $\mathrm{Int}^{*} 、 \mathrm{NDWI}^{* *} 、 \mathrm{NDDI}^{* *} 、 \mathrm{NMDI}^{* *}$ & 0.48 & 0.16 & 0.12 & 8.8 & -126 \\
\hline & 5 & $\mathrm{~B}^{* *}, \mathrm{~B} 11^{* *}, \mathrm{~B} 12^{* *}, \mathrm{~S} 2_{\mathrm{REP}}{ }^{* *}, \mathrm{PVI}^{* *}$ & 0.29 & 0.19 & 0.14 & 22.5 & -111 \\
\hline & 6 & $\mathrm{~B}_{1}{ }^{* *}, \mathrm{~B} 12^{* *}, \mathrm{NDVI}^{* *}, \mathrm{NDWI}^{* *}, \mathrm{NDDI}^{* *} 、 \mathrm{PDI}$ & 0.42 & 0.17 & 0.13 & 16.8 & -115 \\
\hline \multirow{5}{*}{$0 \sim 60$} & 2 & $\mathrm{~S}^{*}, \mathrm{NDDI}^{* *}$ & 0.37 & 0.17 & 0.13 & 7.9 & -131 \\
\hline & 3 & $\mathrm{B1}^{* *}, \mathrm{PVI}^{* *}$, NSDSI3 $^{* * *}$ & 0.46 & 0.16 & 0.12 & 3.6 & -133 \\
\hline & 4 & $\mathrm{SI}^{* *} 、 \mathrm{NDWI}^{* *} 、 \mathrm{NDDI}^{* *} 、 \mathrm{NMDI}^{* *}$ & 0.46 & 0.16 & 0.12 & 6.2 & -129 \\
\hline & 5 & $\mathrm{BI}^{* *}, \mathrm{NDVI}^{* *}, \mathrm{NDWI}^{* *}, \mathrm{NDDI}^{* *}, \mathrm{NMDI}^{* *}$ & 0.49 & 0.15 & 0.12 & 5.3 & -128 \\
\hline & 6 & 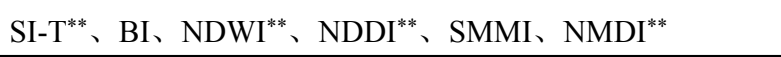 & 0.44 & 0.16 & 0.12 & 11.1 & -121 \\
\hline
\end{tabular}




\section{Table 5 (on next page)}

SSC inversion based on BPNN model. 


\begin{tabular}{llllllll}
\hline \multirow{2}{*}{ Depth (cm) } & Calibration & & & & & Validation & \\
\cline { 2 - 3 } & $\mathrm{R}^{2}{ }_{\text {adj }}$ & RMSE (\%) & MAE (\%) & & $\mathrm{R}^{2}$ adj & RMSE (\%) & MAE (\%) \\
\hline $0 \sim 20$ & 0.48 & 0.20 & 0.13 & & 0.46 & 0.17 & 0.13 \\
$20 \sim 40$ & 0.59 & 0.14 & 0.11 & & 0.61 & 0.15 & 0.11 \\
$40 \sim 60$ & 0.56 & 0.15 & 0.12 & & 0.52 & 0.14 & 0.11 \\
$0 \sim 40$ & 0.53 & 0.17 & 0.12 & & 0.50 & 0.16 & 0.12 \\
$0 \sim 60$ & 0.52 & 0.16 & 0.12 & & 0.51 & 0.15 & 0.12 \\
\hline
\end{tabular}

1 
Table 6(on next page)

SSC inversion based on SVM model. 


\begin{tabular}{llllllll}
\hline \multirow{2}{*}{ Depth (cm) } & Calibration & & & & & Validation & \\
\cline { 2 - 3 } & $\mathrm{R}^{2}{ }_{\text {adj }}$ & RMSE (\%) & MAE (\%) & & $\mathrm{R}_{\text {adj }}^{2}$ & RMSE (\%) & MAE (\%) \\
\hline $0 \sim 20$ & 0.50 & 0.19 & 0.13 & & 0.49 & 0.16 & 0.12 \\
$20 \sim 40$ & 0.56 & 0.15 & 0.11 & & 0.53 & 0.16 & 0.12 \\
$40 \sim 60$ & 0.58 & 0.14 & 0.11 & & 0.55 & 0.14 & 0.10 \\
$0 \sim 40$ & 0.56 & 0.16 & 0.11 & & 0.52 & 0.15 & 0.12 \\
$0 \sim 60$ & 0.59 & 0.15 & 0.11 & & 0.52 & 0.14 & 0.11 \\
\hline
\end{tabular}

1 
Table 7 (on next page)

SSC inversion based on ELM model. 


\begin{tabular}{llllllll}
\hline \multirow{2}{*}{ Depth (cm) } & Calibration & & & & & Validation & \\
\cline { 2 - 3 } & $\mathrm{R}^{2}{ }_{\text {adj }}$ & RMSE (\%) & MAE (\%) & & $\mathrm{R}^{2}$ adj & RMSE (\%) & MAE (\%) \\
\hline $0 \sim 20$ & 0.51 & 0.19 & 0.13 & & 0.49 & 0.16 & 0.13 \\
$20 \sim 40$ & 0.60 & 0.14 & 0.10 & & 0.62 & 0.14 & 0.11 \\
$40 \sim 60$ & 0.58 & 0.14 & 0.11 & & 0.52 & 0.14 & 0.11 \\
$0 \sim 40$ & 0.58 & 0.16 & 0.11 & & 0.55 & 0.15 & 0.12 \\
$0 \sim 60$ & 0.52 & 0.16 & 0.12 & & 0.51 & 0.15 & 0.11 \\
\hline
\end{tabular}

1 


\section{Table 8 (on next page)}

SSC inversion based on RF model. 


\begin{tabular}{llllllll}
\hline \multirow{2}{*}{ Depth (cm) } & Calibration & & & & & Validation & \\
\cline { 2 - 3 } & $\mathrm{R}^{2}{ }_{\text {adj }}$ & RMSE (\%) & MAE (\%) & & $\mathrm{R}^{2}$ adj & RMSE (\%) & MAE (\%) \\
\hline $0 \sim 20$ & 0.62 & 0.17 & 0.10 & & 0.54 & 0.15 & 0.12 \\
$20 \sim 40$ & 0.68 & 0.13 & 0.09 & & 0.63 & 0.14 & 0.11 \\
$40 \sim 60$ & 0.64 & 0.13 & 0.09 & & 0.50 & 0.15 & 0.11 \\
$0 \sim 40$ & 0.65 & 0.14 & 0.09 & & 0.61 & 0.14 & 0.11 \\
$0 \sim 60$ & 0.59 & 0.15 & 0.10 & & 0.53 & 0.14 & 0.12 \\
\hline
\end{tabular}

1 
Figure 1

Study area and sample points location.

(A) Location of JIA in HID. (B) Sample points distribution. 


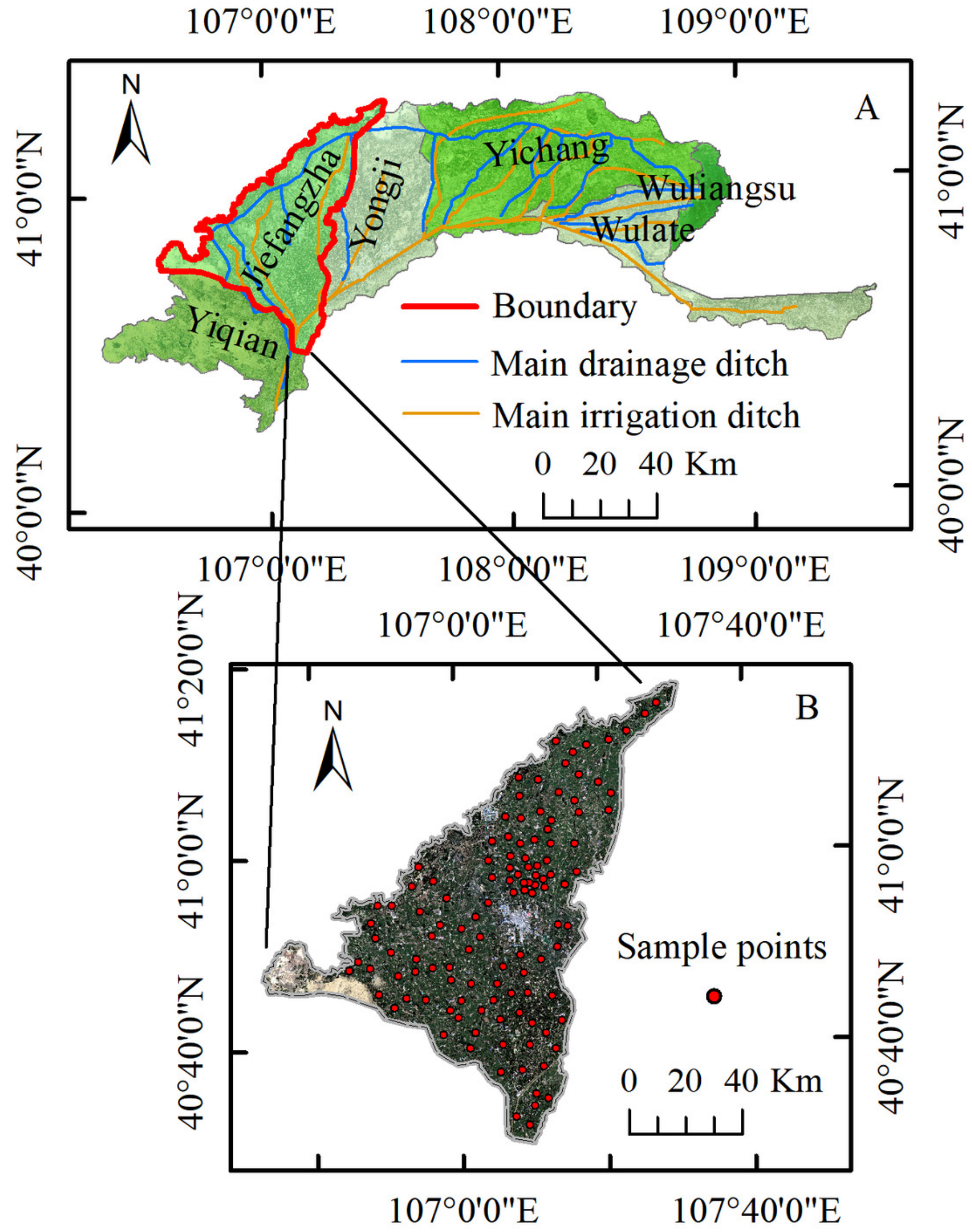


Figure 2

Soil line fitting diagram of JIA.

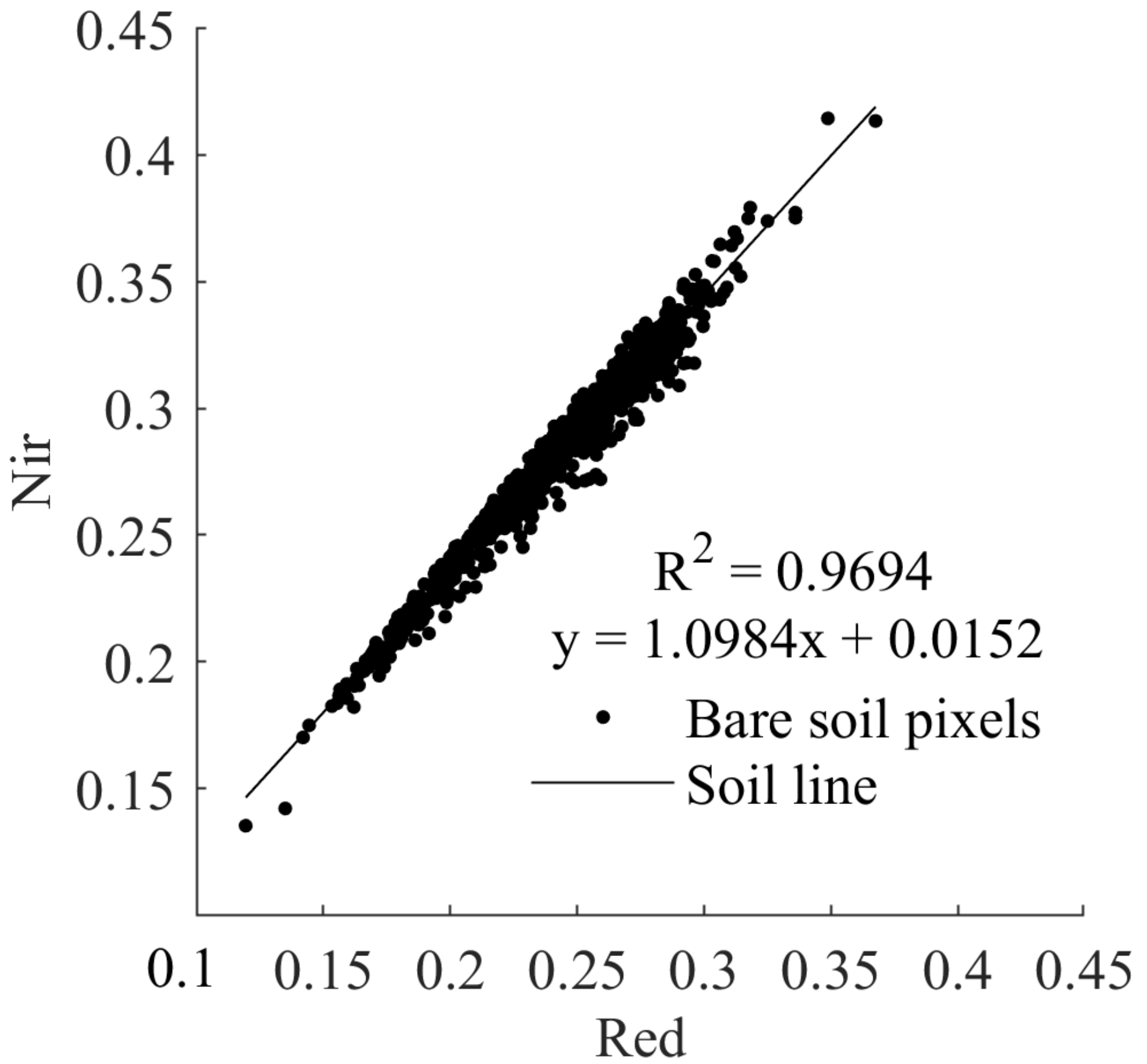


Figure 3

Flowchart of the proposed methodology for SCC estimation. 


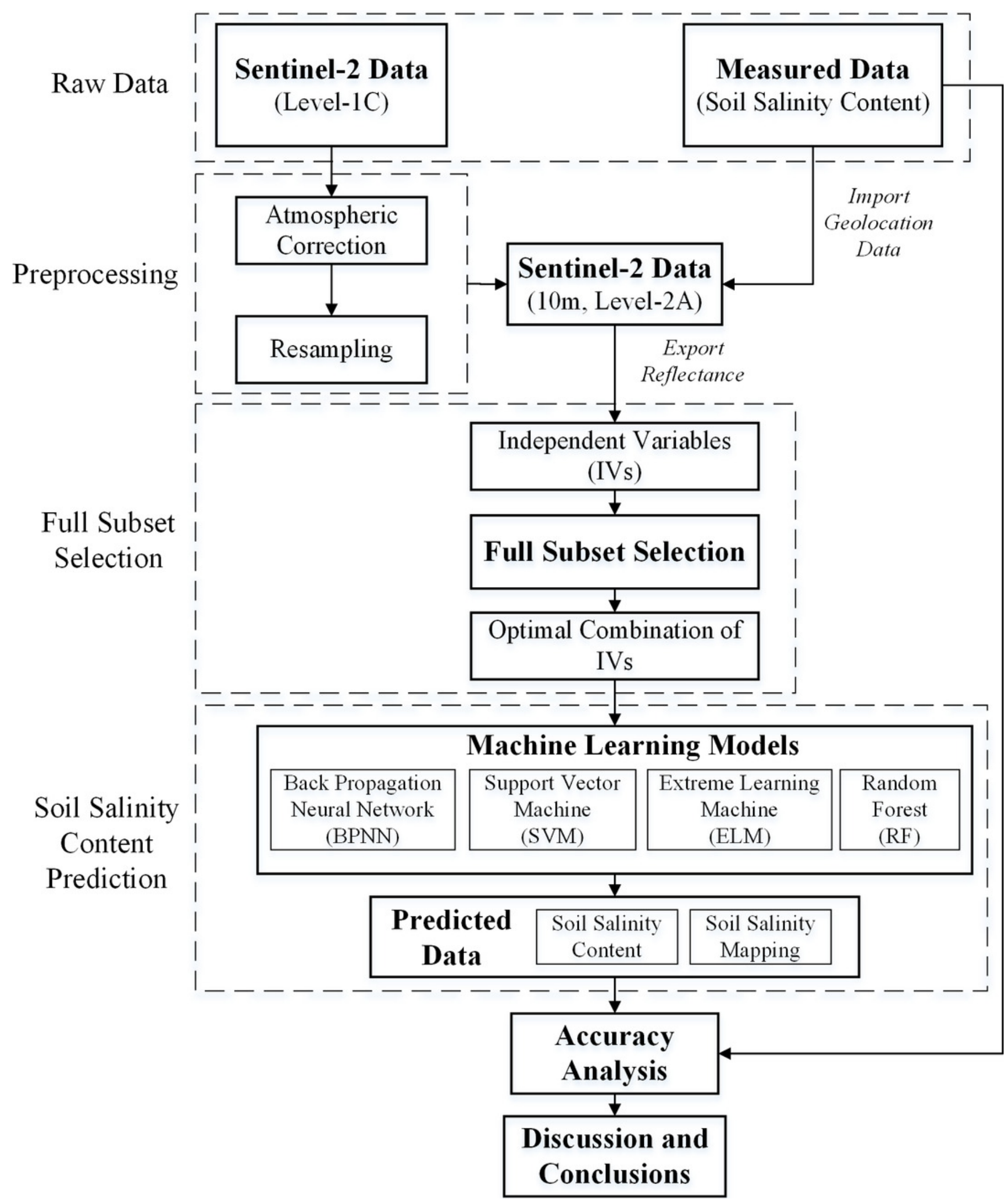


Figure 4

The topological structure of BPNN and ELM.

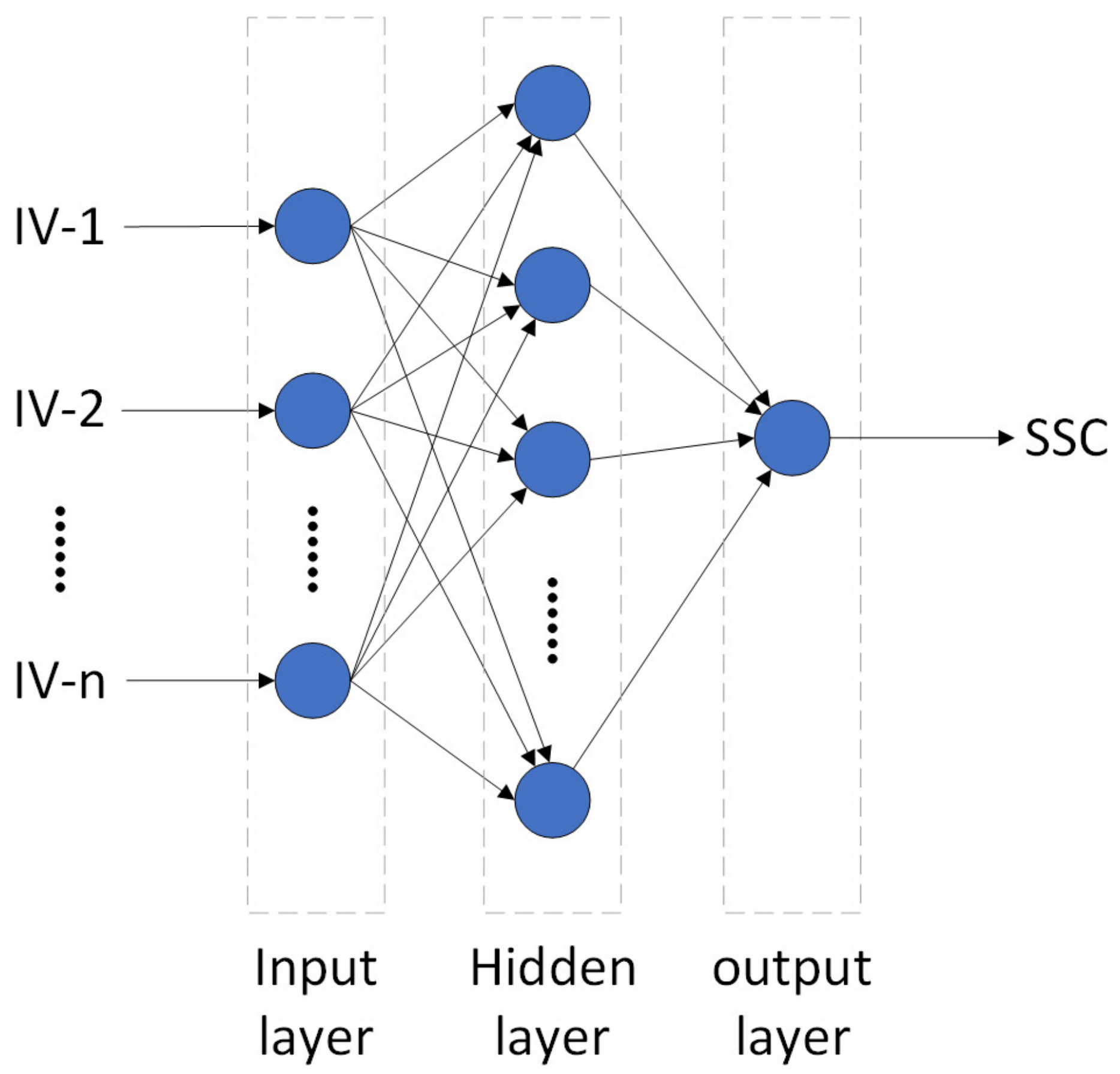


Figure 5

The structure of RF.

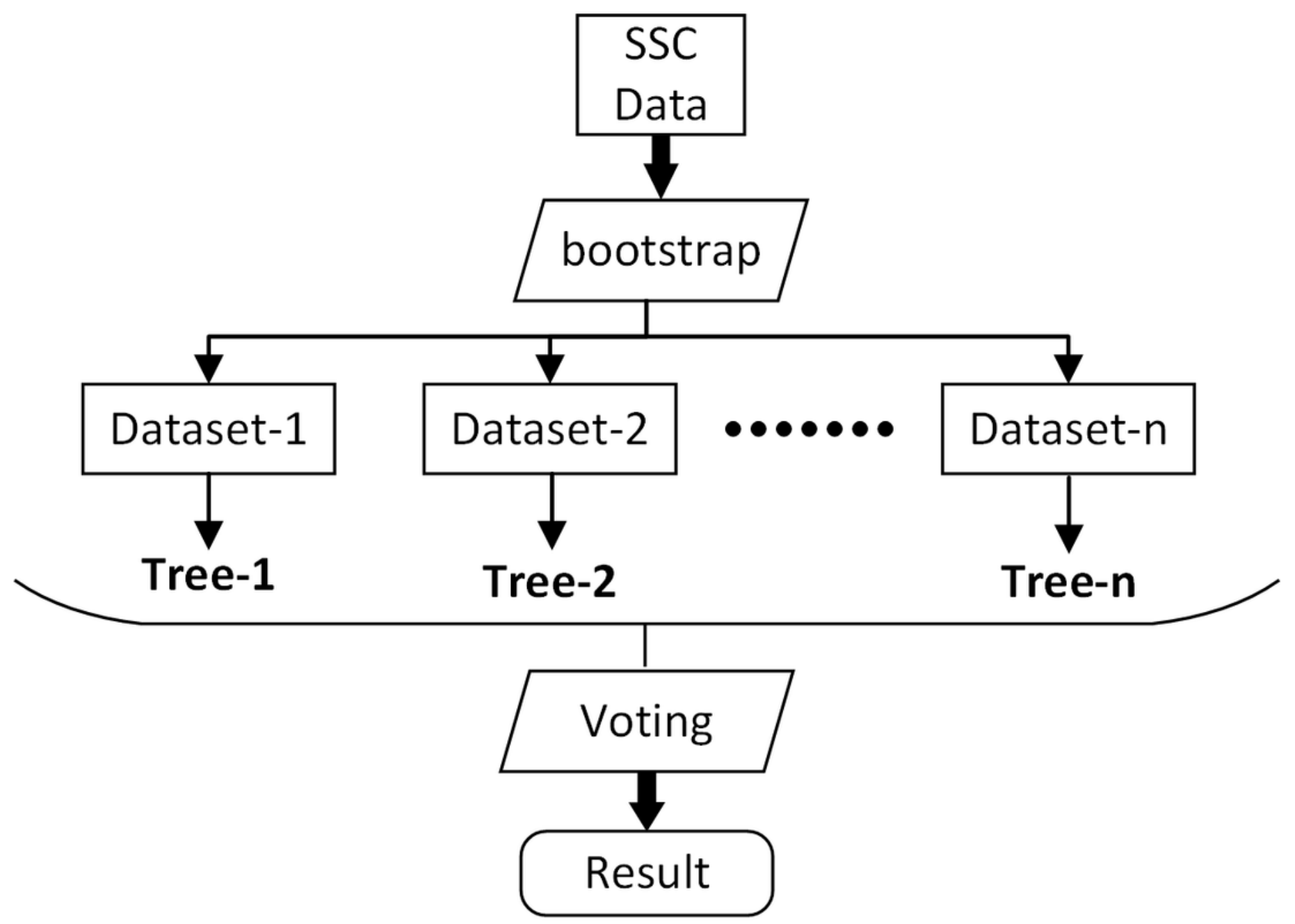


Figure 6

Heatmap of Pearson correlation coefficient between IVs and SSC.

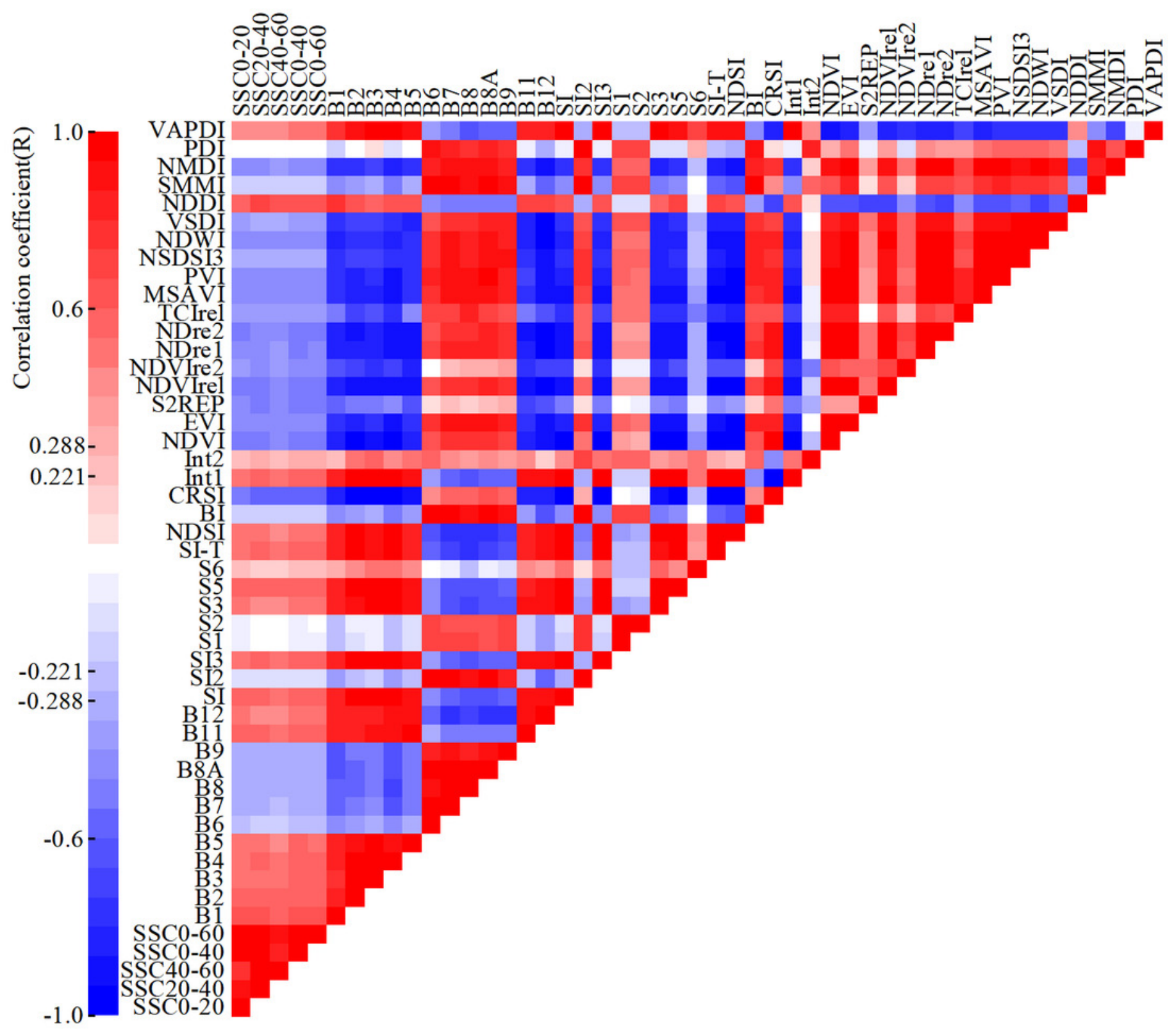


Figure 7

Scatterplots of measured and predicted SSC of BPNN, SVM, ELM and RF models at the best depth.

(A), (B), (C) and (D) are the calibration scatterplots of the four models, respectively. (E), (F), $(\mathrm{G})$ and $(\mathrm{H})$ are the validation scatterplots of the four models, respectively.
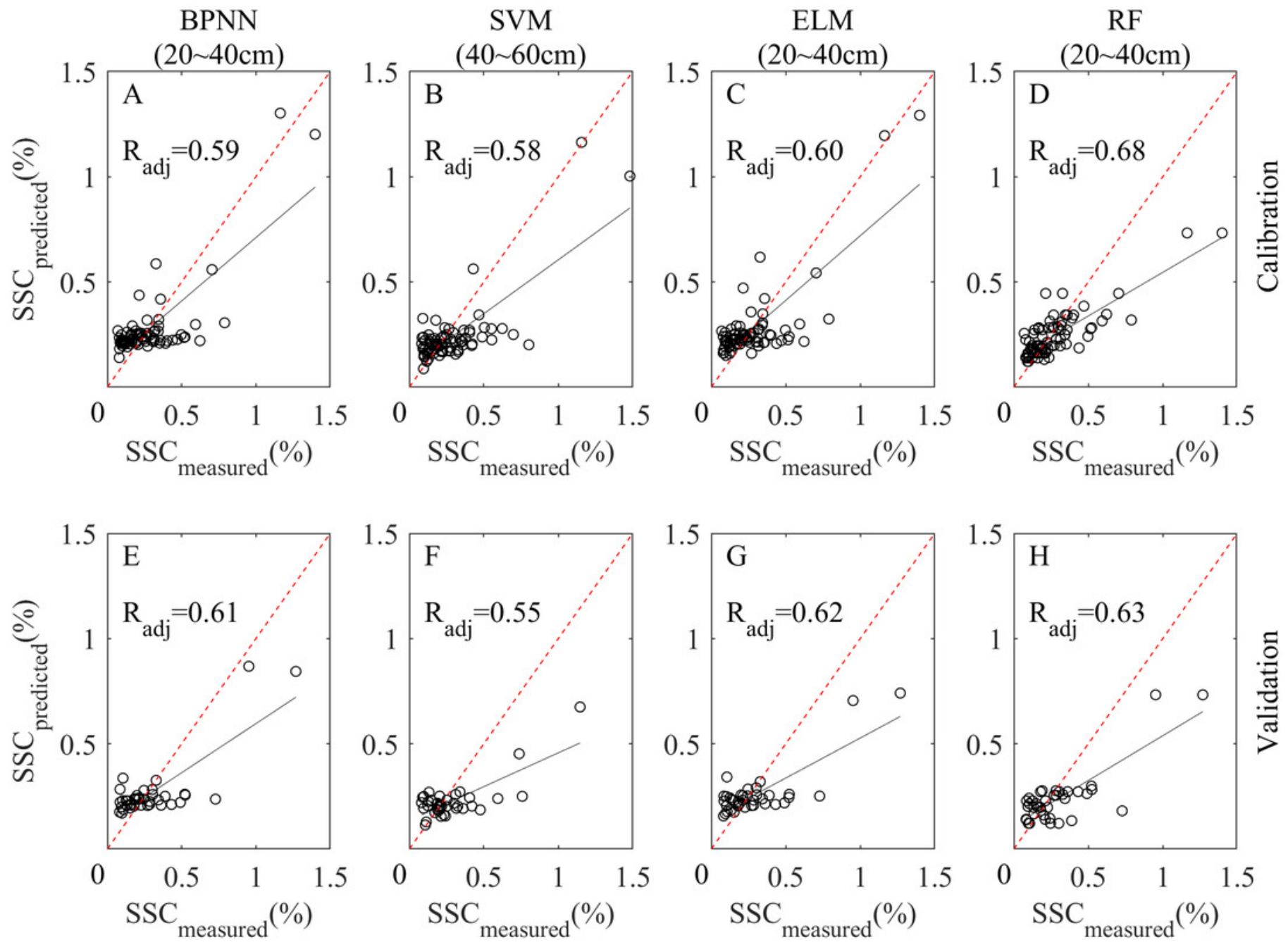
Figure 8

Overall comparative chart of SSC inversion depths.

(A), (B), (C), (D) and (E) are $R_{\text {adj }}^{2}$ of the models at $0 \sim 20 \mathrm{~cm}, 20 \sim 40 \mathrm{~cm}, 40 \sim 60 \mathrm{~cm}, 0 \sim 40 \mathrm{~cm}$ and $0 \sim 60 \mathrm{~cm}$, respectively. (F), (G), (H), (I) and (J) are RMSE of the models at $0 \sim 20 \mathrm{~cm}$, $20 \sim 40 \mathrm{~cm}, 40 \sim 60 \mathrm{~cm}, 0 \sim 40 \mathrm{~cm}$ and $0 \sim 60 \mathrm{~cm}$, respectively. (K), (L), (M), (N) and (O) are MAE of the models at $0 \sim 20 \mathrm{~cm}, 20 \sim 40 \mathrm{~cm}, 40 \sim 60 \mathrm{~cm}, 0 \sim 40 \mathrm{~cm}$ and $0 \sim 60 \mathrm{~cm}$, respectively. 

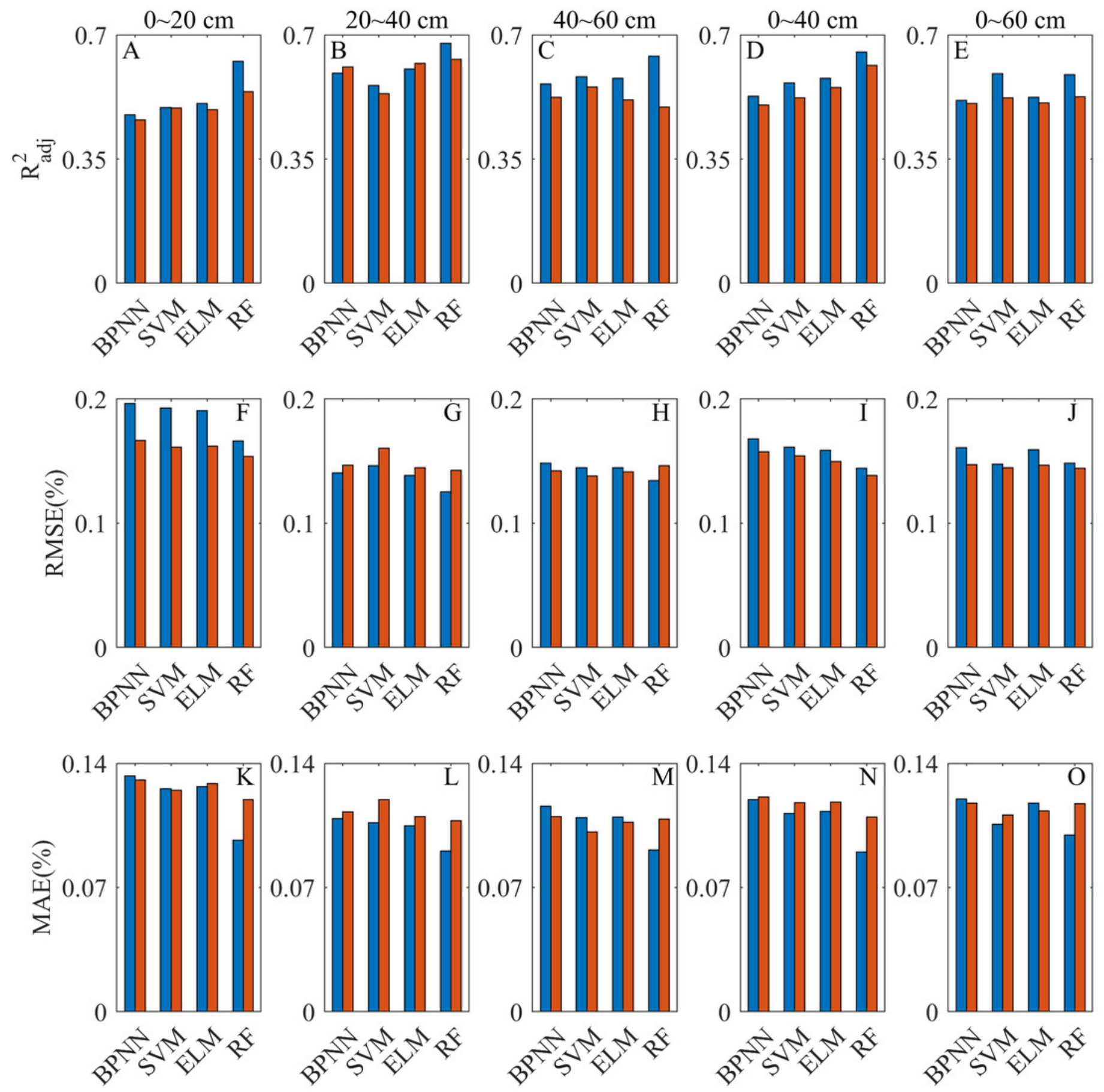

Calibration

Validation 
Figure 9

Overall comparative chart of SSC inversion models.

(A), (B), (C) and (D) are the $\mathrm{R}_{\text {adj }}^{2}$ of BPNN, SVM, ELM and RF model at all depth, respectively.

(E), (F), (G) and (H) are the RMSE of BPNN, SVM, ELM and RF model at all depth, respectively.

(I), (J), (K) and (L) are the MAE of BPNN, SVM, ELM and RF model at all depth, respectively. 

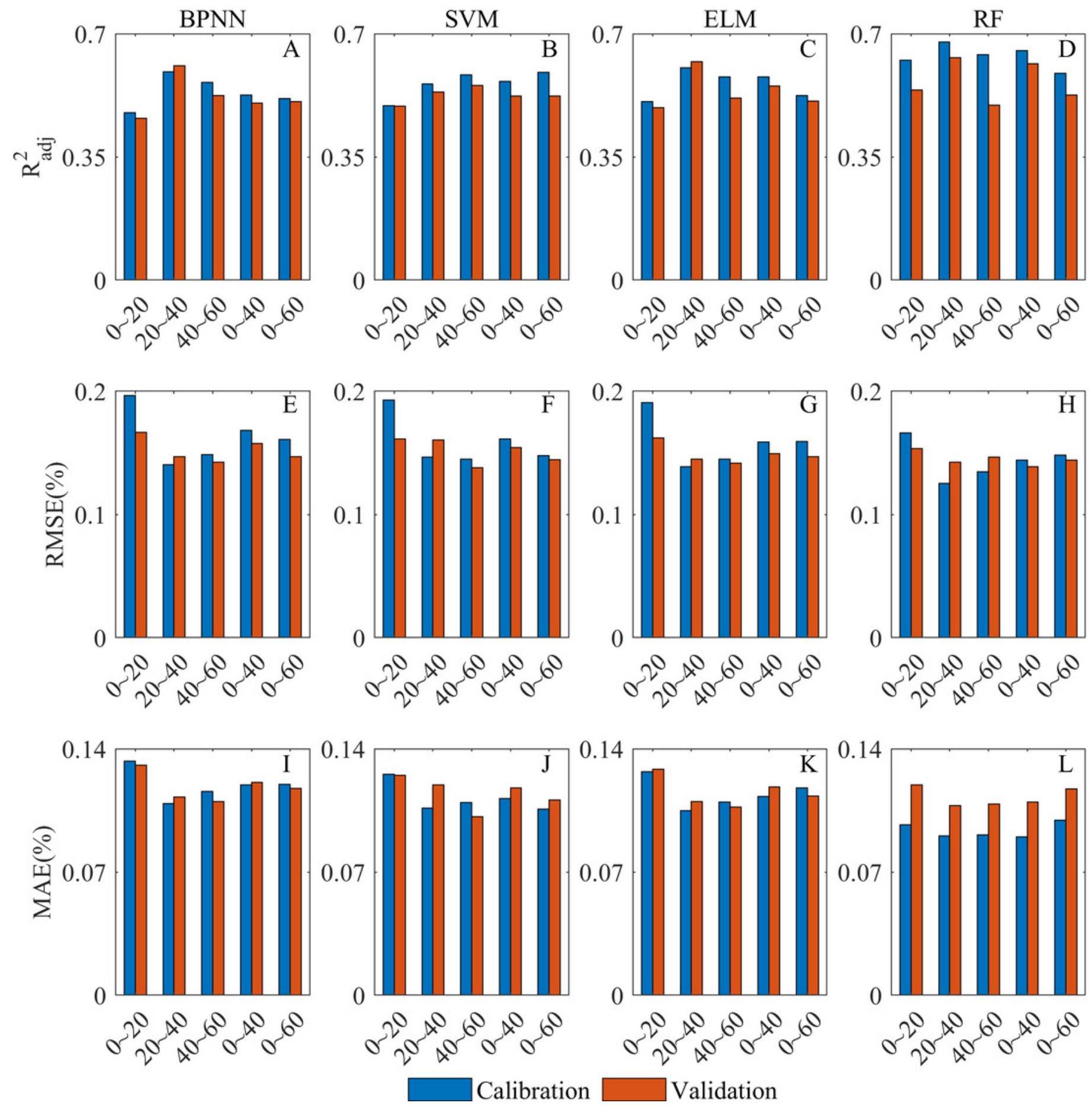
Figure 10

SSC distribution maps of JIA based on RF model.

(A), (B), (C), (D) and (E) are the SSC distribution at $0 \sim 20 \mathrm{~cm}, 20 \sim 40 \mathrm{~cm}, 40 \sim 60 \mathrm{~cm}, 0 \sim 40$ $\mathrm{cm}$ and $0 \sim 60 \mathrm{~cm}$, respectively.
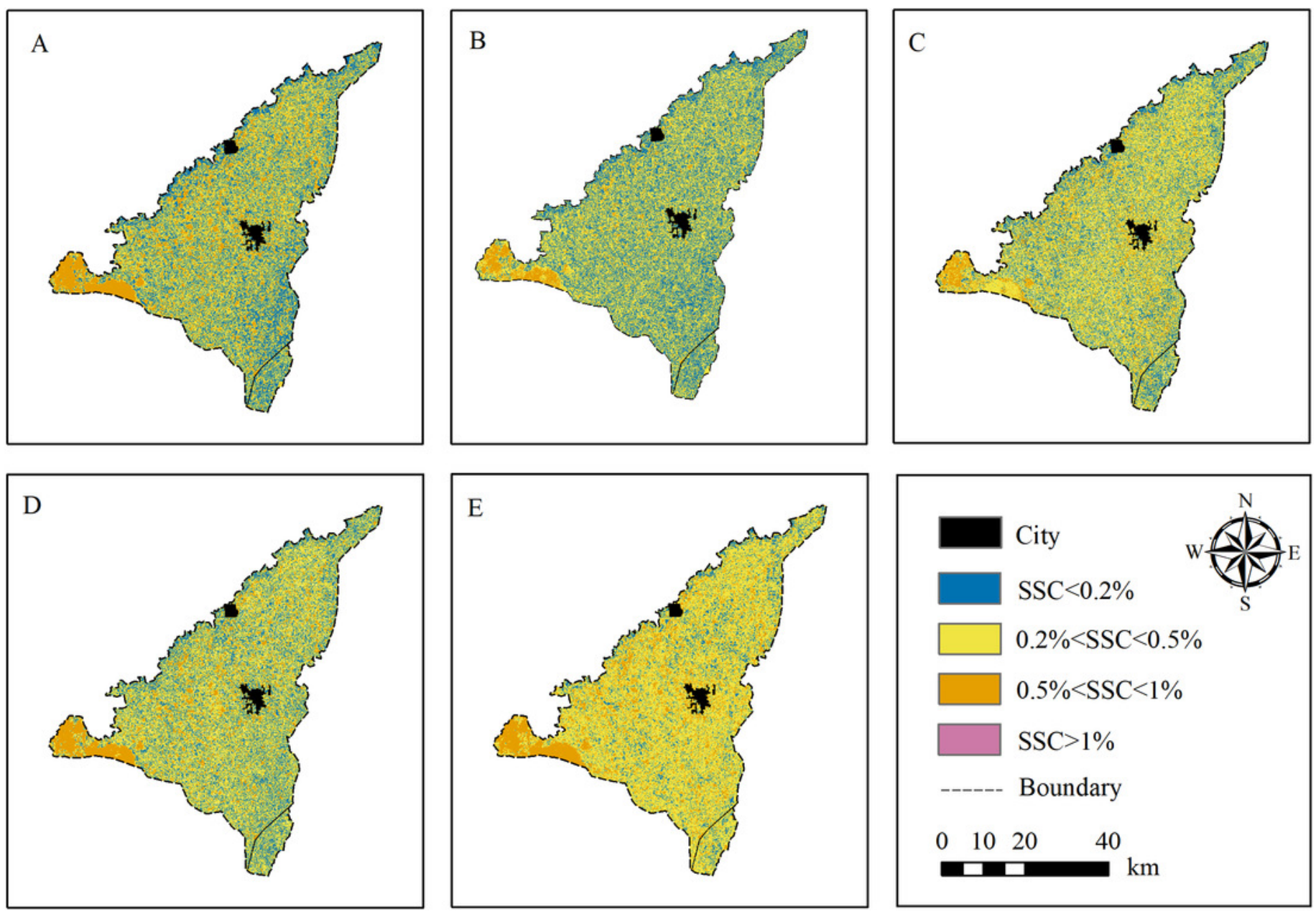